\title{
First Snout with Complete Teeth Row of Small Titanosaur in Indo-Pakistan Found from the Latest Maastrichtian Vitakri Formation of Pakistan; Associated Cranial and Postcranial Skeletons of Saraikimasoom vitakri (Poripuchia, Stocky Titanosauria, Sauropoda) from Pakistan and Referred Fossils from India
}

\author{
Muhammad Sadiq Malkani \\ Geological Survey of Pakistan, Muzaffarabad, Pakistan \\ Email: malkanims@yahoo.com
}

How to cite this paper: Malkani, M.S. (2020) First Snout with Complete Teeth Row of Small Titanosaur in Indo-Pakistan Found from the Latest Maastrichtian Vitakri Formation of Pakistan; Associated Cranial and Postcranial Skeletons of Saraikimasoom vitakri (Poripuchia, Stocky Titanosauria, Sauropoda) from Pakistan and Referred Fossils from India. Open Journal of Geology, 10, 368-407.

https://doi.org/10.4236/ojg.2020.104018

Received: March 13, 2020

Accepted: April 14, 2020

Published: April 17, 2020

\section{Copyright $\odot 2020$ by author(s) and} Scientific Research Publishing Inc. This work is licensed under the Creative Commons Attribution International License (CC BY 4.0).

http://creativecommons.org/licenses/by/4.0/

\begin{abstract}
Titanosaurs articulated cranial elements especially jaw bones with articulated complete teeth row are extraordinarily rare. Here the holotypic snout with articulated jaw bones and complete teeth row of Saraikimasoom vitakri are being presented which has international significance and contributes to understanding the evolutionary relationships and paleobiogeographic history of the vertebrates of Indo-Pakistan subcontinent. The completeness of the skeleton, in particular the presence of a well-preserved skull has a significant influence on resolution of titanosaur phylogeny. Here Saraikimasoom vitakri holotypic snout from South Kinwa, and referred jaw with articulated pointed and rounded teeth along with associated postcranial fossils from north Kinwa, and other associated materials from Mari Bohri, mid-Sangiali, Zubra Basti Nala and Grut localities of Pakistan are being presented. All these assemblages show consistent results.
\end{abstract}

Keywords

Titanosauria, Stocky Poripuchia, Snout, Skeletons, Saraikimasoom, South Asia

\section{Introduction}

Dinosaurs from India are known from about 2 centuries since 1828 [1]-[7], while 
dinosaurs from Pakistan are known first time in 2000 [8]. Five taxa of titanosaurs from Pakistan were established like Pakisaurus, Sulaimanisaurus and Khetranisaurus of Pakisaurids and Marisaurus and Balochisaurus of Balochisaurids [9]. Many fossils were referred to Marisaurus [10] [11] [12] [13] [14], Balochisaurus [13] [14] [15] and Pakisaurus [16]. Saraikimasoom and Gspsaurus were established on snout and partial skulls [17]. Nicksaurus and Maojandino were established on cranial and associated postcranial materials [18] [19]. Recently four titanosaur taxa were recognized from Indo-Pakistan [20] [21] [22] [23] [24], Vitakridrinda [25] and Vitakrisaurus [25] [26] [27] large sized theropods, Induszalim [25] [28] [29], Pabwehshi [30] and Sulaimanisuchus [25] [26] mesoeucrocodiles, and many other biotas [31] [32] from Pakistan. Due to lack of snout or anterior skull materials from Indo-Pakistan, here the detail description of snout, cranial and postcranial materials from Pakistan are being presented.

Titanosaurs postcrania are found worldwide, but their skulls are exceptionally rare [33] but here first snout GSP/MSM-142-4 with articulated elements and complete teeth row of Saraikimasoom vitakri titanosaur found from Pakistan are being presented. This snout specimen is of international significance and contributes to understanding the evolutionary relationships and paleobiogeographic history of the vertebrates of Indo-Pakistan subcontinent. This snout piece is the only piece of sauropod jaw bones known from the Indo-Pakistan subcontinent and is extremely important. It includes both upper and lower jaw bones as well as teeth. The lower jaw teeth are overlapped by upper jaw. The morphology of teeth within the jaw bones can be revealed on CT scans. Cranial material is known from only ten titanosaurs and is limited to isolated elements and fragmentary braincases [34] [34] [35] [36]. In fact, no titanosaur skull found in association with postcrania has ever been fully described or illustrated, and very few instances of direct association of skulls and postcrania have been documented. This nagging lack of association has left even the most basic skeletal morphology of the clade controversial and has precluded detailed study of the higher and lower level phylogeny of the group [34] [35] [36]. The completeness of the skeleton and, in particular, the presence of a well-preserved skull, has a significant influence on resolution of titanosaur phylogeny [37]. Here I provide a description of the holotypic snout from South Kinwa 4, and referred jaw with articulated pointed and rounded teeth and associated postcranial from north Kinwa $4 \mathrm{n}$, and other associated materials from Mari Bohri 15, Sangiali 1, Zubra Basti Nala 7, Grut 9, mid-Bor 2 and Top Kinwa 16 of Saraikimasoom vitakri from Pakistan; all these sites revealed consistent results.

The skulls of most derived titanosaurs are scarce in the global world, while Saraikimasoom has holotypic skull. The Rapetosaurus have disarticulated skull while the present snout have articulated teeth and jaw bones. For clarification of Cretaceous-Paleogene mass extinction, the latest Cretaceous titanosaurs are again scarce, while the present cranial and associated postcranial fossils are found at the time of Cretaceous-Paleogene mass extinction and are significant for studying mass extinction. Saraikimasoom vitakri provide the cranial comparison 
facility with coeval and other sauropod dinosaurs like Rapetosaurus of Gondwana and Nemegtosaurus and Quaesitosaurus of Mongolia Asia (Laurasia) and also type series postcranial materials provide comparison with Isisaurus colberti, Pakisaurus and other world wide titanosaurs based on postcrania. In this way these cranial and postcranial fossils and their characters are also significant for phylogenetic and evolutionary study of titanosaurs and Gondwanan paleobiogeographic affinity.

\section{Saraikimasoom vitakri}

The systematic paleontology of Saraikimasoom vitakri is as follows.

Dinosauria [38];

Saurischia [39];

Sauropoda [40];

Titanosauria [41];

Poripuchia [22];

Gspsauridae [17];

Saraikimasoom [17] [19];

Saraikimasoom vitakri [17] [19];

(Figures 1-9).

The holotypic skull MSM-142-4 (Figure 1) (Figure 2) was found from south Kinwa 4 just $10 \mathrm{~m}$ south from small peak which is about 50 meters west to Kinwa spring. This skull resembles the teeth and alveoli characters of MSM-138-4n (Figure 5) which belongs to Balochisaurus deduced on Balochisaurus caudal vertebrae (Figure 5). The anterior most part of the snout was partially exposed and remaining portion was excavated from shale of host Vitakri Formation. The referred materials are found from north Kinwa 4n (Figure 3) south Kinwa 4 and mid Kinwa (Figure 3), Sangiali 1 (Figures 4-6), Mari Bohri (Figure 7) (Figure 8), Top Kinwa 16 (Figure 9), Dada Pahi 17 (Figure 9), south Zubra Basti Nala 7 (Figure 9) and Grut Gambrak 9 (Figure 9) of Barkhan district, Sulaiman (Middle Indus) basin, and a Karkh locality (Figure 9) of Khuzdar district, Kirthar (Lower Indus) Basin, Balochistan, Pakistan. Only one distal end of dorsal vertebra rib or may be neural spine (Figure 9) collected from Karkh area, Khuzdar district, Kirthar (lower Indus) basin. The holotypic and referred specimens found from Pakistan are housed in the Museum of the Geological Survey of Pakistan, Quetta. Further one elongated cylindrical holotypic caudal vertebra (out of 2 holotypic vertebrae) of Titanosaurus blanfordi [3] [42], caudal vertebra K27/501 and distal stocky tibia K27/508 from Pisdura India of Titanosaurus blanfordi [4] referred to Saraikimasoom vitakri. Further holotypic large caudal vertebra UCB 92829 of Titanosaurus madagascariensis from Madagascar [42] [43] show close resemblance to Saraikimasoom due to strong ventral compression. The caudal vertebrae from Pisdura India were referred to Saraikimasoom vitakri due to strong ventral compression of anterior/middle caudal centrum, long cylindrical distal caudal with prominent articular ring and without restricted posterior articular ball are the characteristic of Saraikimasoom vitakri. 

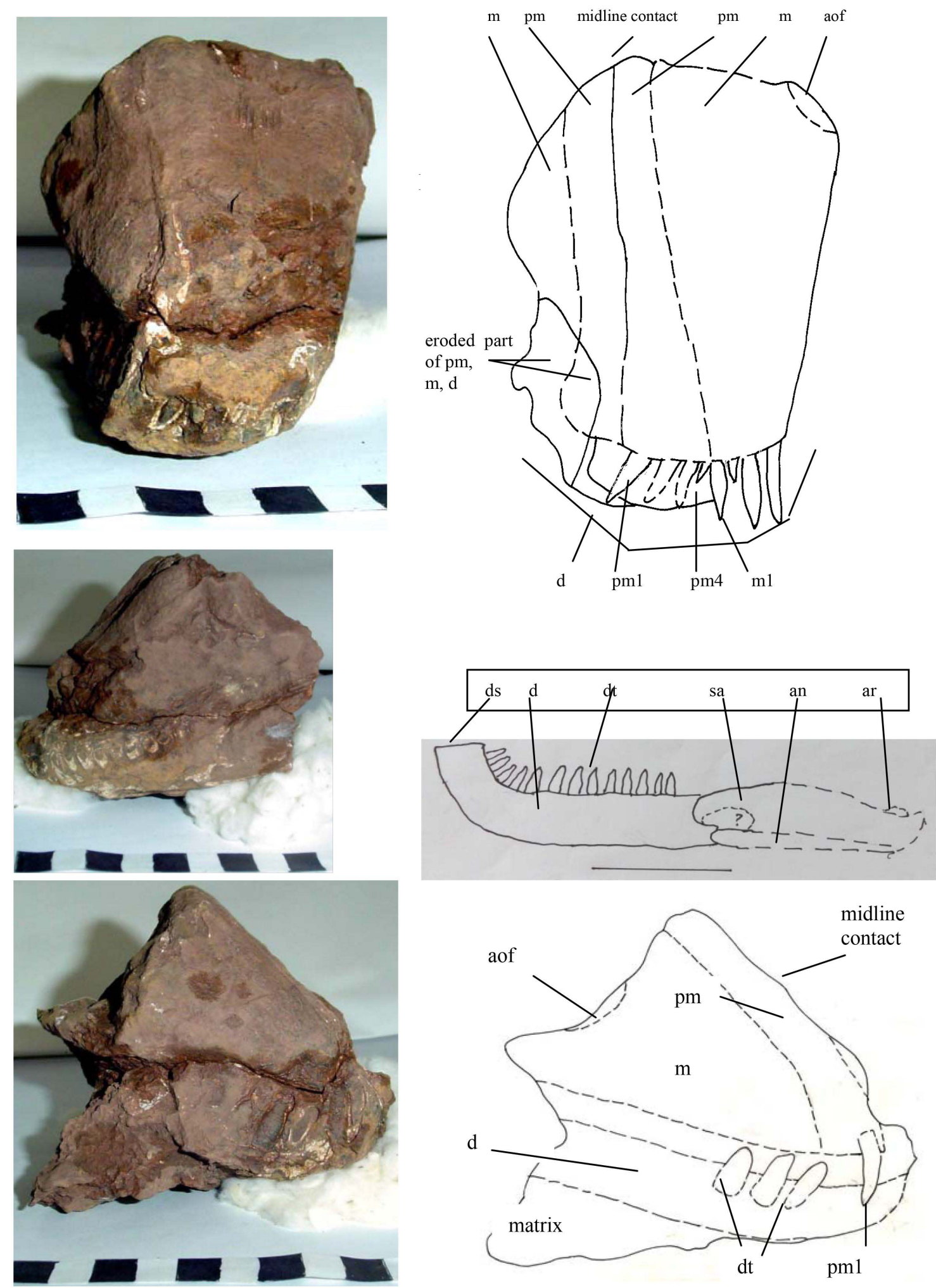

Figure 1. Photographs and line drawings of skull (rostrum) articulated with mandible (MSM-142-4) of Saraikimasoom vitakri collected from south Kinwa 4 (partially exposed and partially excavated), anterior view. Scale each black digit is 1 centimeter $(\mathrm{cm})$. Abbreviation; an, angular; ar, articular; aof, antorbital fenestra; d, dentary; ds, dentary symphysis; $\mathrm{dt}$, dentary teeth; $\mathrm{m}$, maxilla; $\mathrm{mc}$, maxillary canal; $\mathrm{ml}$, midline contact, $\mathrm{mt}$, maxillary teeth, pm, premaxilla; pt, pterygoid; sa, surangular. Arabic numerals following abbreviations refer to tooth position (e.g. pm 4). 

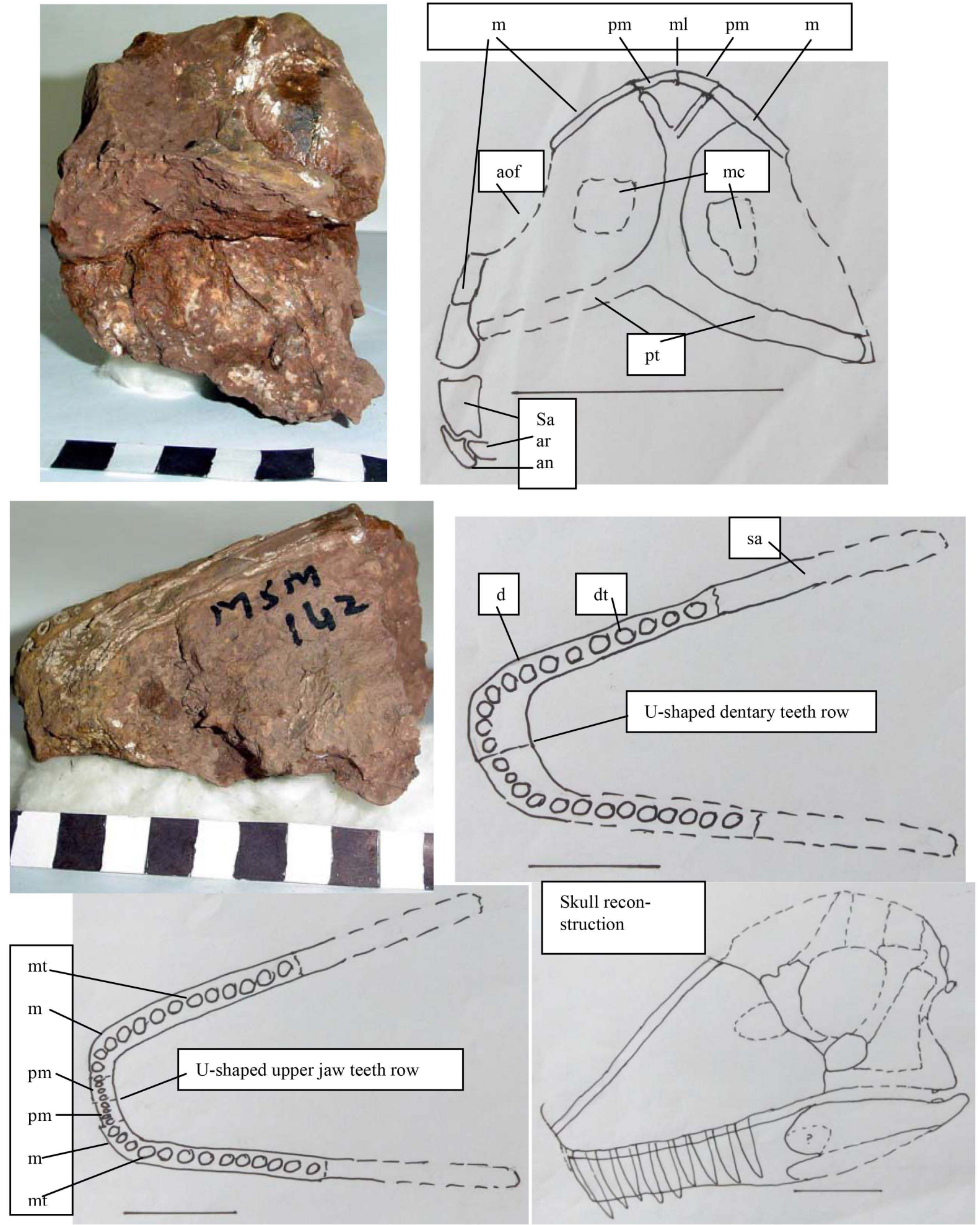

Figure 2. Photograph and line drawings of skull (rostrum) articulated with mandible (MSM-142-4) of Saraikimasoom vitakri collected from south Kinwa 4 (partially exposed and partially excavated), right lateral view (upper), posterior view (middle) and ventral view (lower). Scale each black digit is 1 centimeter $(\mathrm{cm})$. For abbreviation pl. see Figure 1. GSP-Geological Survey of Pakistan. MSM-Muhammad Sadiq Malkani. The formal specimen numbers are like GSP/MSM-142-4 but briefly represented by MSM-142-4 in literature. The central number 142 represents the serial number and last number 4 represents locality number of Kinwa. 


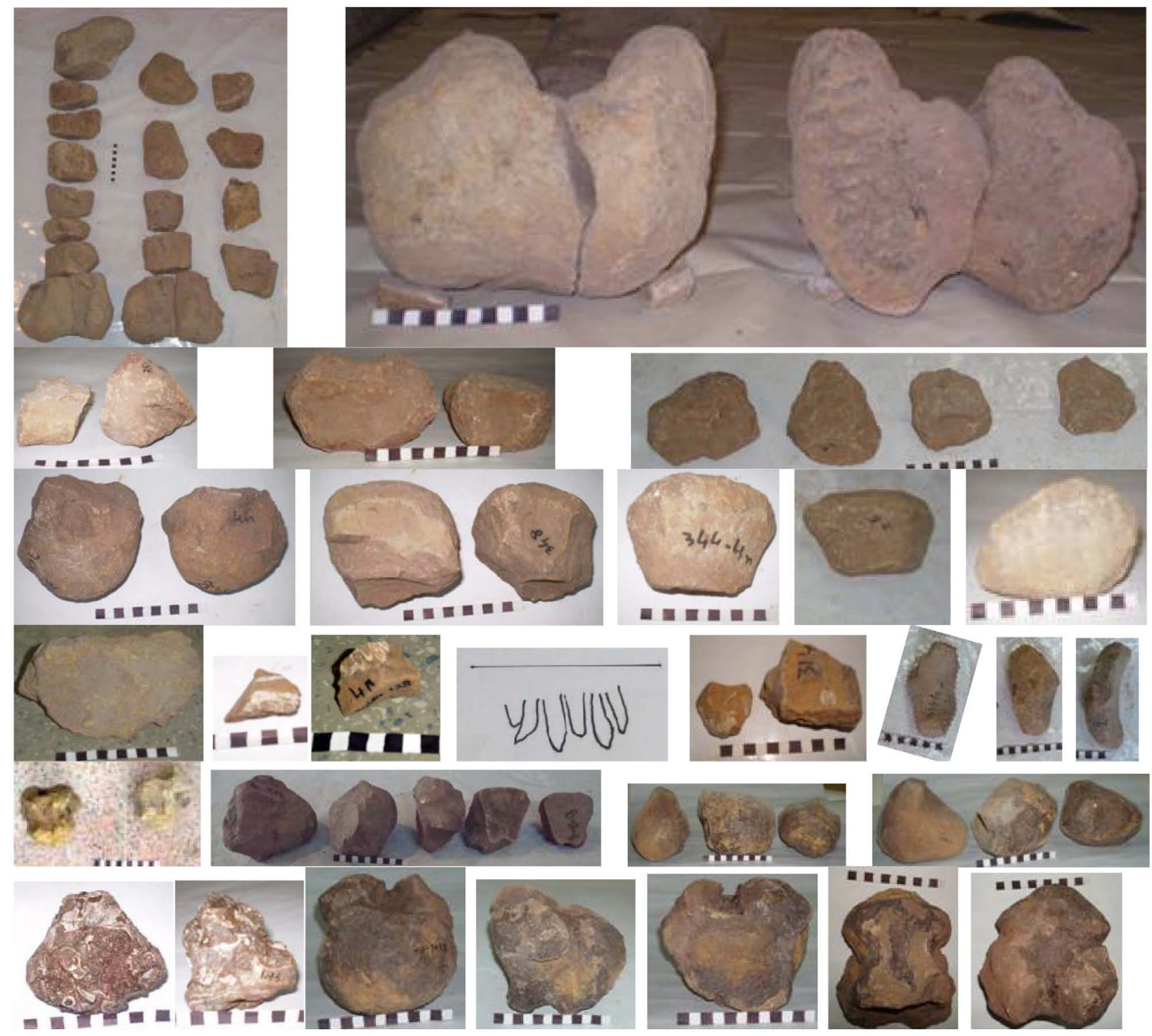

Figure 3. Saraikimasoom vitakri referred fossils from north Kinwa 4n (row 1 - 4), south Kinwa 4 (row 5, p1, 2) and mid Kinwa 4 m (rows 5, p3, 4; row 6). Nicksaurus razashahi holotypic skeleton (rows 1 - 4) was found from north Kinwa [19], which is now being referred to Saraikimasoom vitakri due to cranial overlapping. Row 1, photo 1/p1, column 1, left femur MSM-190-4n; column 2, a pair of tibia (left and right distal tibiae MSM-346-4n, MSM-345-4n); femur sections MSM-378-4n, MSM-270-4n; distal femur MSM-192-4n; column 3, humerus parts MSM-380-4n, MSM-377-4n, MSM-379-4n, MSM-438-4n; p2, a pair of distal femora (left and right distal femur MSM-190-4n, MSM-192-4n). Row 2, p1, cervical vertebrae MSM-382-4n, MSM-381-4n; p2, cervical vertebrae MSM-381-4n, MSM-382-4n; p3, cervical vertebra MSM-381-4n, cervical/dorsal vertebra MSM-212-4n, cervical vertebra MSM-382-4n and MSM-383-4n. Row 3, p1, p2, caudal vertebrae MSM-347-4n and MSM-348-4n; p3, 4, 5, proximal radius MSM-344-4n. Row 4, p1, spongy proximal pubis with glenoid surface MSM-1096-4n; p2, 3, 4, six teeth in jaw ramus MSM-138-4n and line drawings; 5 , skull and teeth fragments in matrix MSM-315-4n and MSM-314-4n; p6, 7, 8, anteroposteriorly compressed possibly posterior caudal chevron MSM-313-4n. Row 5, p1, caudal vertebrae MSM-50-4, MSM-51-4; p2, caudal vertebrae MSM-512-4, MSM-514-4, MSM-811-4 MSM-515-4, MSM-808-4; p3, 4, caudal vertebrae MSM-1021-4m (north), MSM-1018-4m (north) and MSM-1019-4m (north). Row 6, broad caudal vertebra MSM-1016-4m in 2 views; midcaudal vertebra MSM-1017-4m-south in different 5 views. Scale each black or white digit is $1 \mathrm{~cm}$.

While the Gspsaurus pakistani have restricted posterior articular ball of posterior caudal vertebrae. The transversely expanded distal tibia show affinity to 


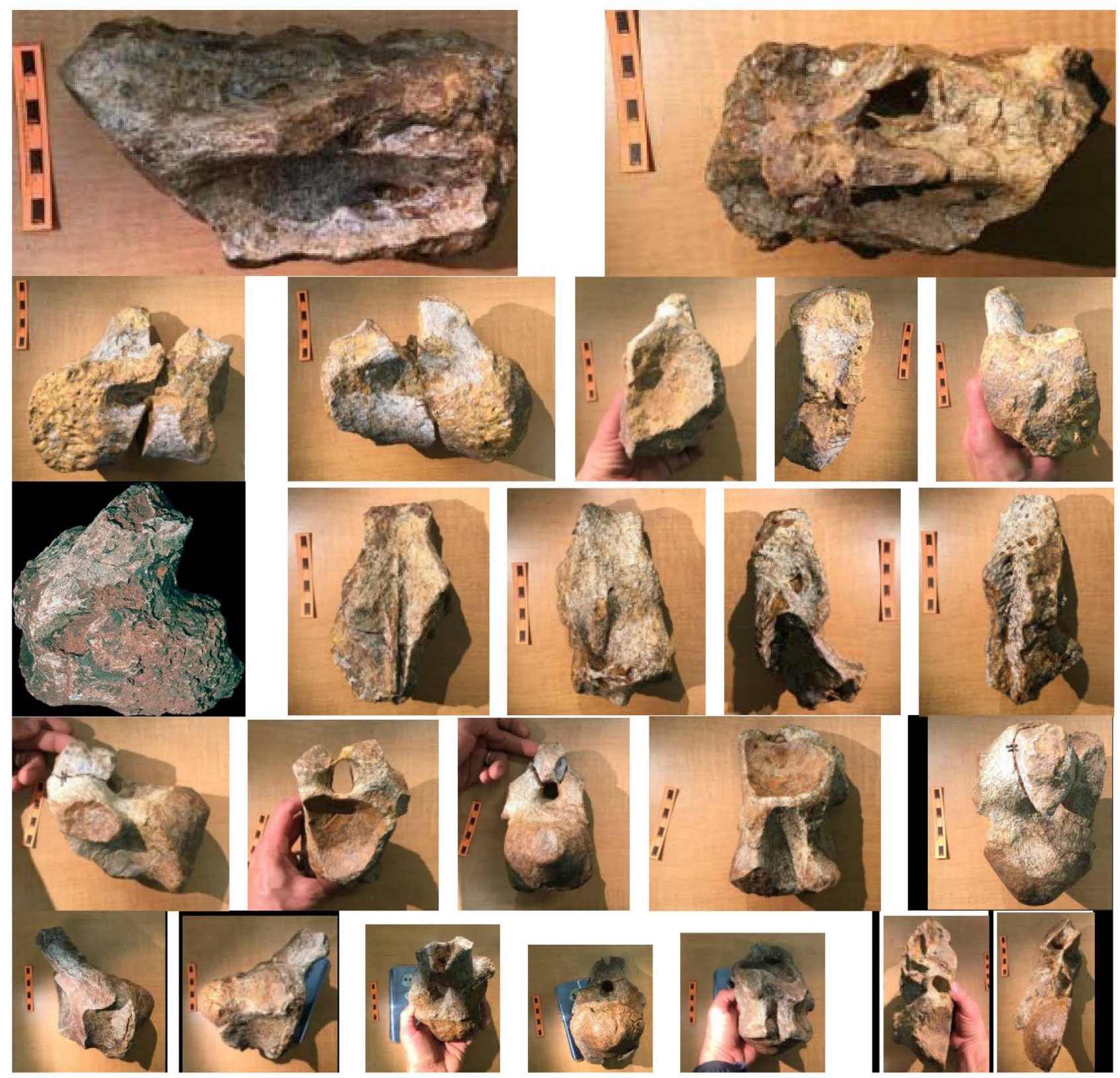

Figure 4. Saraikimasoom vitakri referred remains from Sangiali 1. Row 1, Cervical vertebra GSP/Sangiali-1101 in 2 views. Row 2 , cervicodorsal vertebra GSP/Sangiali-1102 in 5 views. Row 3, dorsal vertebra GSP/Sangiali-1103; dorsal vertebra neural arch GSP/Sangiali-1104 in 4 views. Row 4, caudal vertebra GSP/Sangiali-1105 in 5 views. Row 5, caudal vertebra GSP/Sangiali-1106 in 5 views; caudal vertebra GSP/Sangiali-1107 in 2 views. Scale each black unit is $1 \mathrm{~cm}$ (total scale $7 \mathrm{~cm}$ ). Figure 4 and Figure 5 represent the possible skeleton of Saraikimasoom vitakri from mid Sangiali 1 locality.

both Gspsaurus pakistani and Saraikimasoom vitakri due to transverse expansion. This is the only proximal tibia which is the key element or guide marker element to differentiate between these two stocky titanosaurs. The Saraikimasoom vitakri have subcircular shaped stockier (with almost equal transverse and anteroposterior widths) proximal tibia, while the Gspsaurus pakistani have convex lense shaped stocky proximal tibia. Pakisaurus balochistani and Isisaurus colberti have proximal flattened tibia but their distal tibia are differentiated. 


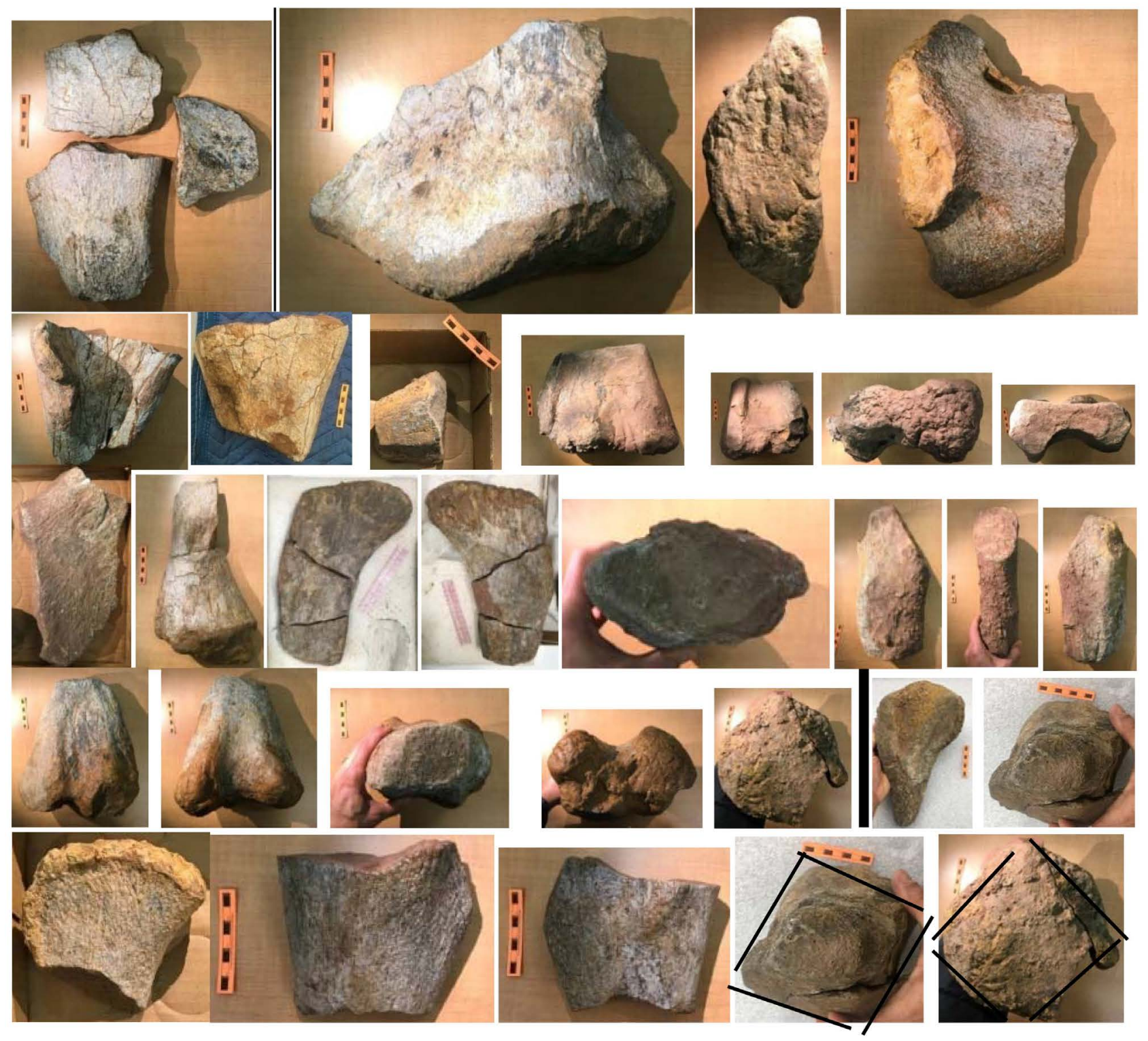

Figure 5. Saraikimasoom vitakri fossils from mid Sangiali 1. Row 1, photo 1/p1, proximal left scapula GSP/Sangiali-1108 (top left image), proximal left scapula GSP/Sangiali-1109 (top right image), and left mid scapula GSP/Sangiali-1110 (lower image); p2, 3, distal left scapula GSP/Sangiali-1111; p4, left Coracoid GSP/Sangiali-1112. Row 2, proximal right humerus GSP/Sangiali-1113; right humerus cross section GSP/Sangiali-1114; distal right humerus GSP/Sangiali-1115 in 4 views. Row 3, partial proximal left pubis GSP/Sangiali-1116; distal left pubis GSP/Sangiali-1117; proximal left femur GSP/Sangiali-1118 in posterior and anterior views; right proximal and mid femur GSP/Sangiali-1119 in 4 views. Row 4, left distal femur GSP/MSM-1-1 in 4 views; left proximal tibia GSP/Sangiali-1120 in 3 views. Row 4, proximal left fibula GSP/Sangiali-1121; mid left fibula GSP/Sangiali-1122 in 2 views with clear lateral trochanter; left typical proximal tibia GSP/Sangiali-1120 subsquare shaped in 2 views. Scale each black unit is 1 $\mathrm{cm}$ (total scale $7 \mathrm{~cm}$ ), while in proximal femur scale is total $15 \mathrm{~cm}$ or 6 inches. Note, at places the locality name with locality number are mentioned as like mid Sangiali 1, here mid Sangiali is the locality name and 1 is the locality number. At places south Kinwa locality number is represented by 4 or $4 \mathrm{~s}$, mid Kinwa locality number is represented by $4 \mathrm{~m}$, and north Kinwa locality number is represented by $4 \mathrm{n}$.

Pakisaurus balochistani have relatively more transversely broad distal tibia or more ratio $(0.80)$ of transverse width of distal tibia to transverse width of proximal tibia to than Isisaurus colberti ratio (0.64). 


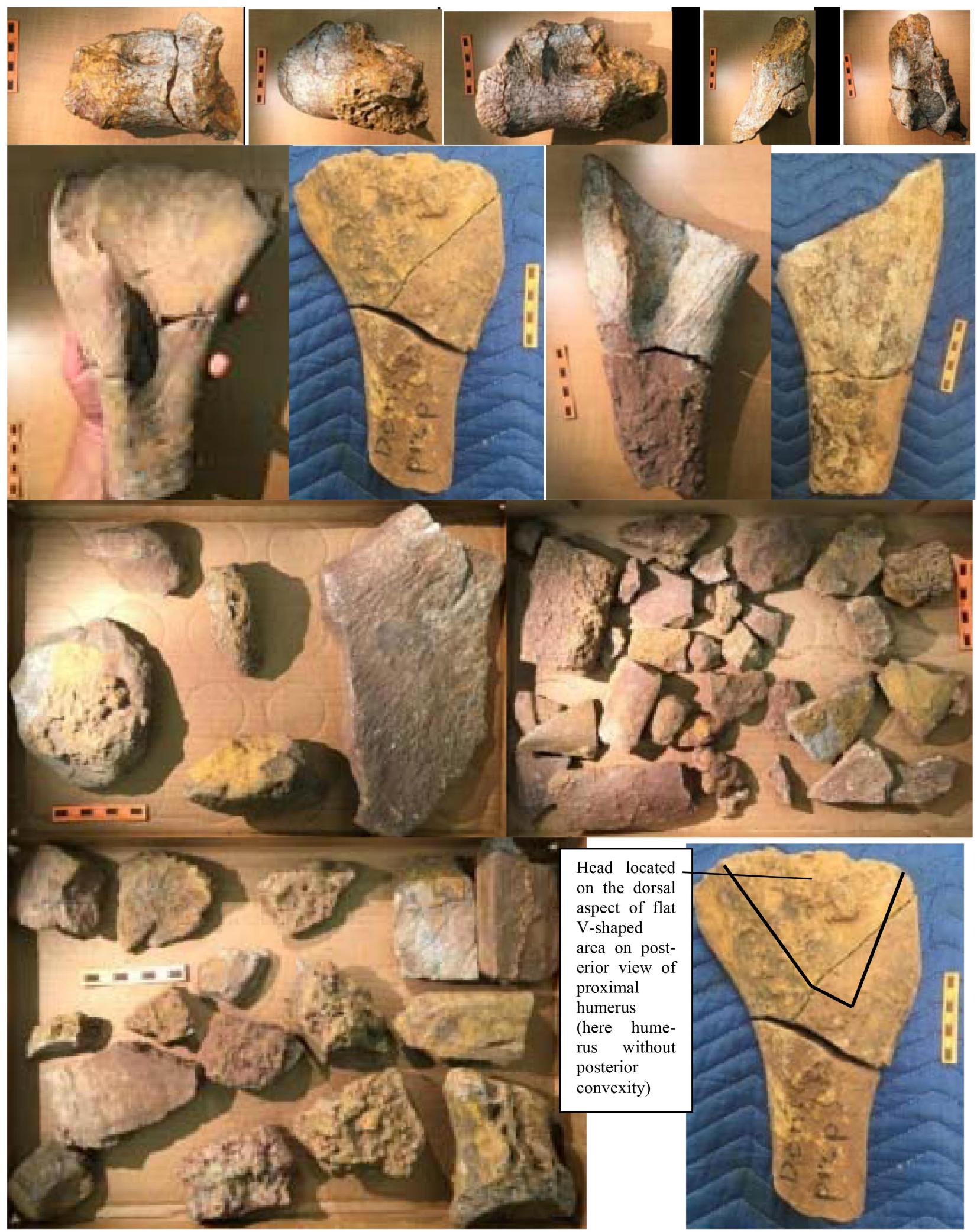

Figure 6. Saraikimasoom vitakri fossils from mid Sangiali 1. Row 1, cervicodorsal vertebra GSP/Sangiali-1123. Row 2, proximal right humerus GSP/Sangiali-1124; proximal right humerus GSP/Sangiali-1125. Row 3, 4, miscellaneous fossils GSP/Sangiali-1126 to GSP/Sangiali-1175; last photo, proximal right humerus GSP/Sangiali-1125 posterior view with in general V-shaped flat, smooth and plain area just below the head. Scale each black unit is $1 \mathrm{~cm}$ (total scale $7 \mathrm{~cm}$ ). 


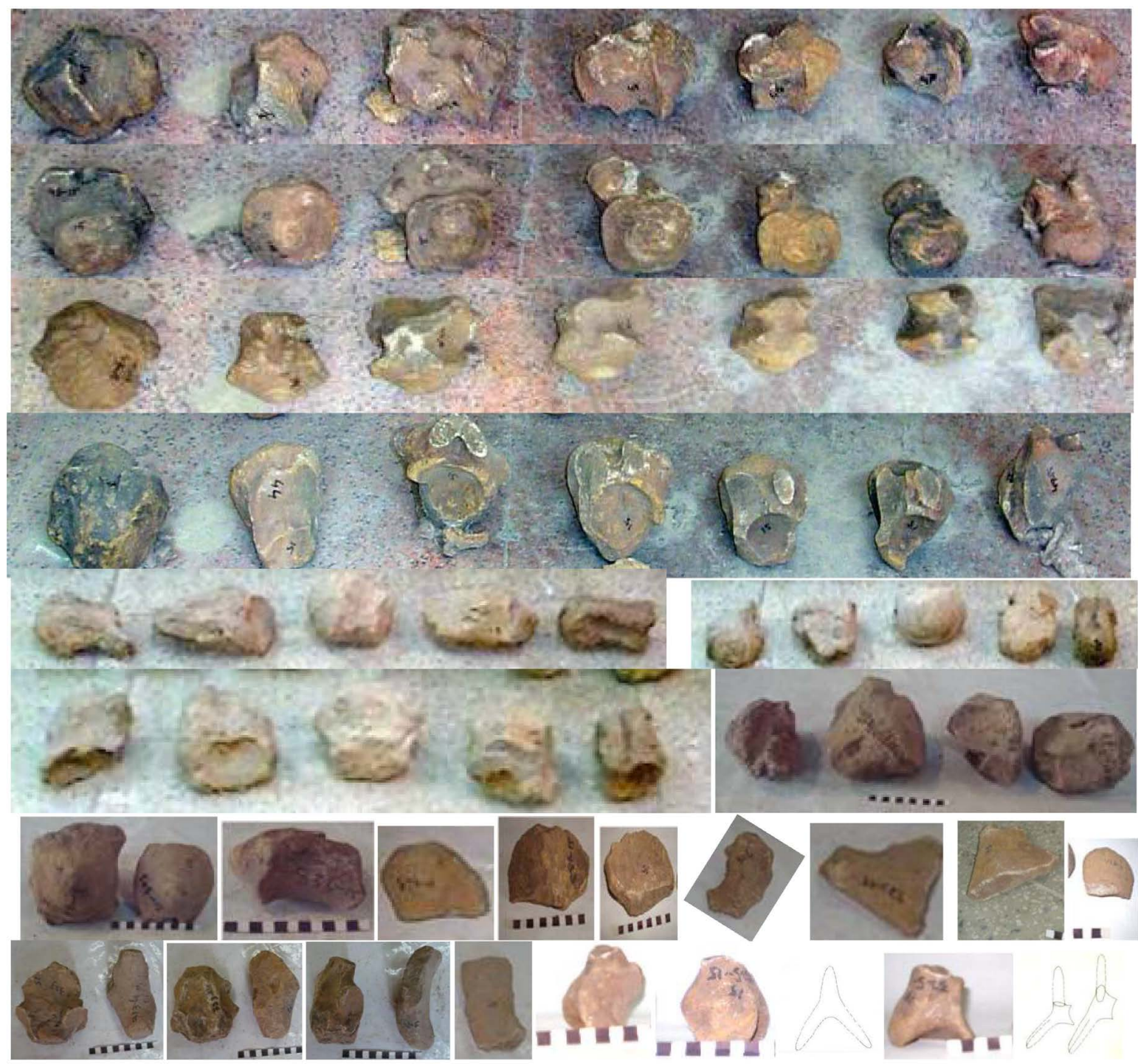

Figure 7. Saraikimasoom vitakri referred skeletal remains from Mari Bohri 15. The holotypic skeleton (rows 1 - 8; and also continued in Figure 8) of Balochisaurus malkani was found from Mari Bohri type locality. Here this holotype (Figure 7) (Figure 8) of Balochisaurus malkani which is being referred to Saraikimasoom vitakri due to some vertebral and limb elements overlapping with its north Kinwa exemplar. Rows 1, 2, 3, 4, caudal vertebrae MSM-43-15 (biconvex first caudal), MSM-44-15, MSM-44a-15, MSM-45-15, MSM-46-15, MSM-47-15, MSM-48-15 in lateral, posterodorsal and posteroventral views [9]. Row 5, five presacral vertebrae MSM-126-15, MSM-127-15, MSM-128-15, MSM-129-15, MSM-130-15 in lateral and anterior views; Row 6, five presacral vertebrae MSM-126-15, MSM-127-15, MSM-128-15, MSM-129-15, MSM-130-15 in posterodorsal view; and four presacral vertebrae MSM-824-15, MSM-823-15, MSM-8-15, MSM-818-15; Row 7, two caudal vertebrae MSM-260-15, MSM-505-15; caudal vertebra MSM-834-15 with prominent articular ring; proximal fibula/unknown/distal rib MSM-672-15; cervical rib MSM-881-15 in 2 views, caudal inclined posteriorly neural spine MSM-324-15; proximal rib of dorsal vertebra MSM-322-15 in 2 views; and distal rib/neural spine MSM-1056-15. Row 8, dorsal neural spine with post zygapophyses and prespinal laminae of dorsal vertebra MSM-323-15 and chevron MSM-313-4n in three views; mid rib MSM-531-15 of dorsal vertebra; distalmost caudal centrum MSM-325-15 in anterior and posterior views with line drawing and lateral views with line drawing. Scale, each black/white digit is $1 \mathrm{~cm}$. For other photos scale pl. See [9] [15].

The Saraikimasoom vitakri referred skeletal remains from north Kinwa 4 n are represented by associated cranial and postcranial skeleton (Figure 3 ). The north 

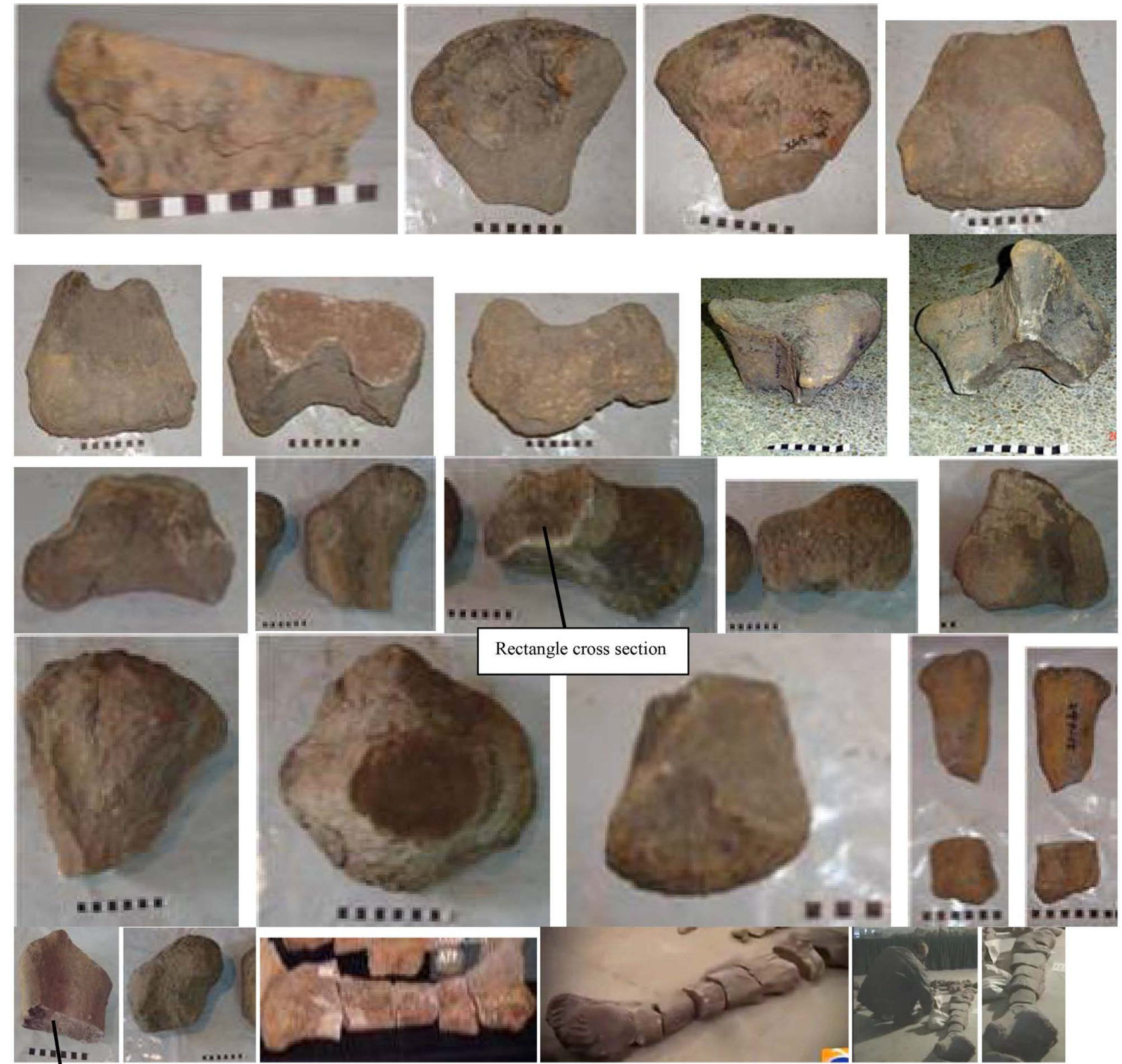

Rectangle cross section

In
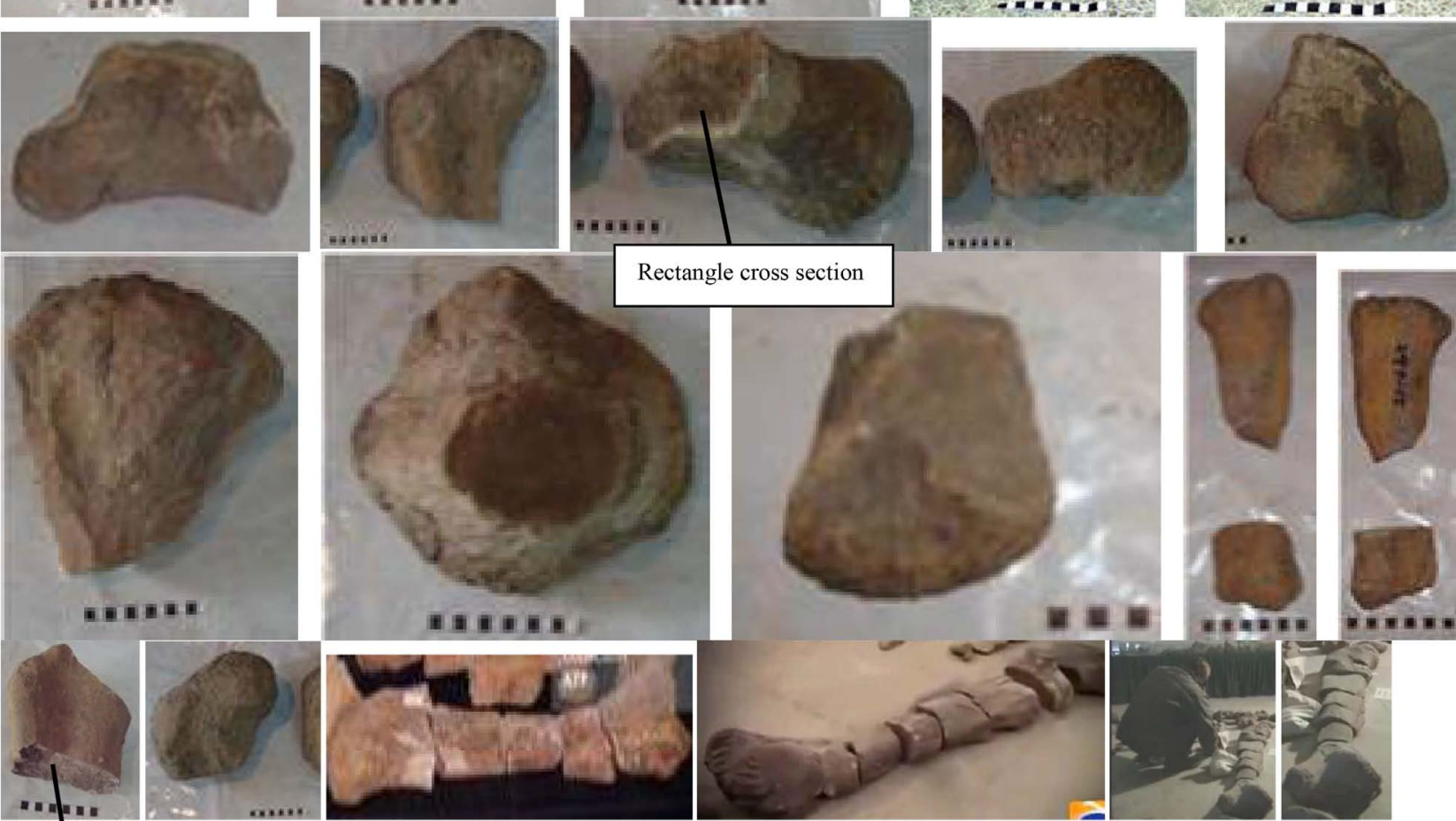

Rectangular cross section of femur

Figure 8. Saraikimasoom vitakri referred skeleton from Mari Bohri 15. Holotype of Balochisaurus malkani (rows 1, 2, 3 and 4, and also continued from Figure 7). Here this holotype (Figure 7) (Figure 8) of Balochisaurus malkani is being referred to Saraikimasoom vitakri due to some overlapping with its north Kinwa exemplar. Row 1, left anterior sternal MSM-675-15; left proximal humerus MSM-245-15 in anterior and posterior views; and distal humerus MSM-174-15 in anterior view. Row 2, distal left humerus MSM-174-15 in posterior, dorsal and ventral views; left proximal ulna MSM-78-15 in posterior and ventral views. Row 3, left acetabulum MSM-166-15 in ventral view for scale pl. See [15]; left proximal femur MSN-168-15 in posterior, ventral and dorsal views; and distal left femur MSM-173-15 in posterior view. Row 4, proximal left tibia in lateral and ventral views MSM-246-15; distal tibia/ulna MSM-227-15; proximal metacarpal MSM-297-15 (upper) and distal metacarpal MSM-750-15 (lower) in 2 views. Row 5, p1, 2, Balochisaurus malkani referred proximal right femora MSM-749-15 and MSM-167-15. P3, 4, 5, 6 show some miscellaneous fossils photos from GSP museum, Quetta, Balochistan. Scale, each black/white digit is $1 \mathrm{~cm}$.

Kinwa $4 \mathrm{n}$ site is located on the west of main Kinwa stream at the junction of northern way/track bending westward from north Kinwa toward Vitakri village 


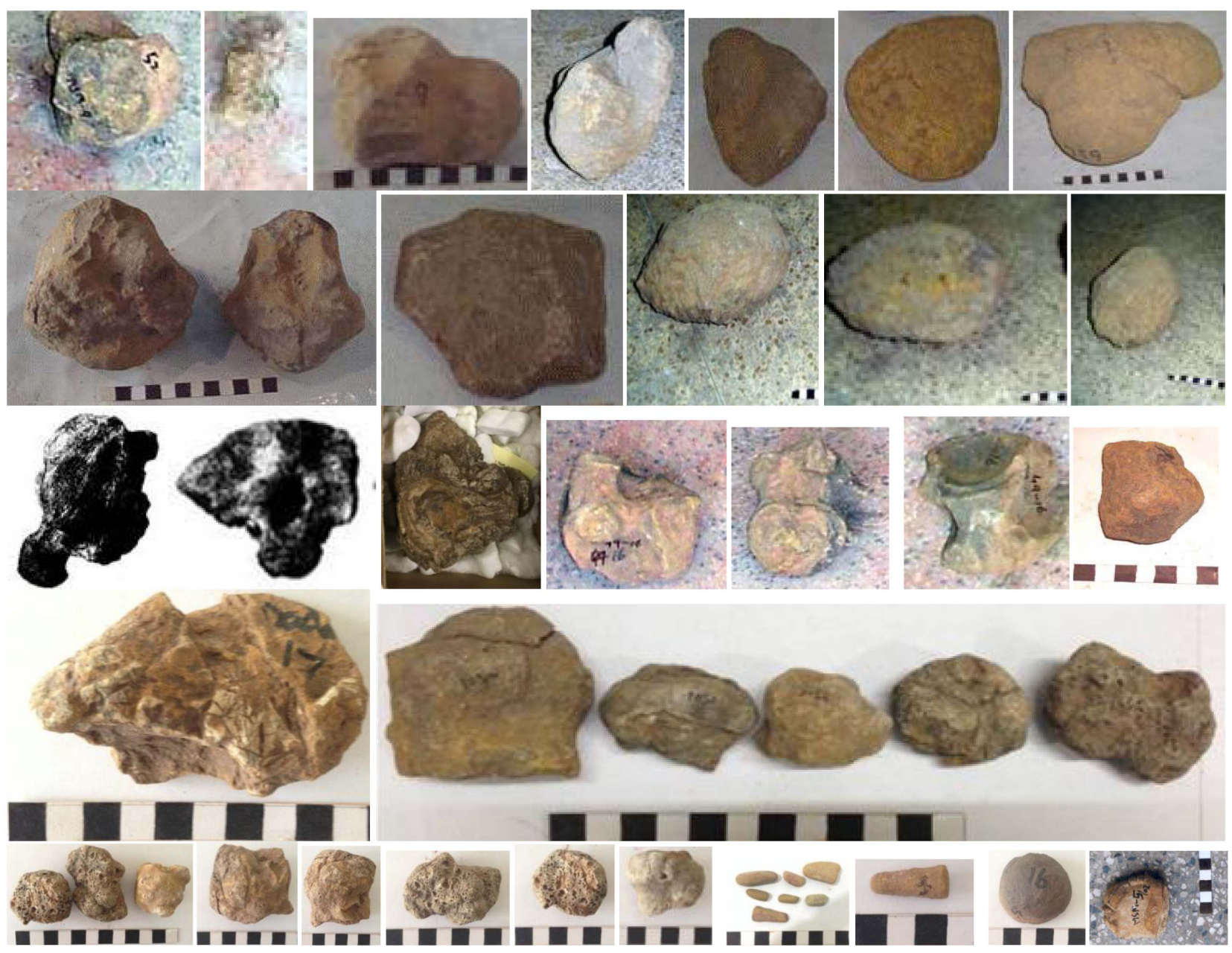

Figure 9. Saraikimasoom vitakri referred fossils. Row 1, Saraikimasoom vitakri Grut 9 Gambrak exemplar mid caudal vertebra MSM-52-9 in 2 views; caudal vertebra MSM-793-9; stocky distal tibia MSM-75-9; right astragalus MSM-752-9 (transverse length $15 \mathrm{~cm}$, anteroposterior width $10 \mathrm{~cm}$ ); distal ulna MSM-252-9; proximal humerus with prominent head (mosaic of samples MSM-694-9 and MSM-759-9). Row 2, Saraikimasoom vitakri South Zubra 7 exemplar, mid caudal vertebrae in ventral view MSM-523-7 and MSM-524-7; right mid scapula in lateral view MSM-746-7; osteoderms large oval ellipsoidal plate MSM-84-7 in 3 views. Row 3, Saraikimasoom vitakri referred fossils of eastern Top Kinwa. Braincase (GSP/MSM-2-16; GSP-UM 7000) in 3 views; caudal vertebra MSM-49-16 in 3 views; metacarpal MSM-1036-16. Row 4, p1, Saraikimasoom vitakri Dada Pahi 17 referred subrectanglesuboval shaped mosaic type osteoderms or may be cranial element MSM-1095-17; p2, five vasicular/spongy coprolite fossils MSM-1050, MSM-1051, MSM-1052, MSM-1053 and MSM-154 of dinosaurs collected from Vitakri dome, Barkhan district, Balochistan. Row 5, p1-6, vasicular/spongy coprolite fossils; p7, 8, teeth impressions or nodules; p9, egg or egg like nodule; p10, distal rib or dorsal neural spine MSM-5/02-Karkh (first bone from Kirthar basin/lower Indus basin). Scale each black or white digit is $1 \mathrm{~cm}$. For other photo/plates scale pl. See [9] [15].

via and along Bor stream to Vitakri village [15]. It is necessary to mention that there is another southern way from south Kinwa 4 water spring and just north of host type locality peak to Pakisaurus type locality to then top sandstone terraine to nearby lower Bor Pakisaurus skeleton and then end lower portion of Bor stream and then Vitakri village. The associated cranial and postcranial remains from north Kinwa $4 \mathrm{n}$ were established as holotype (Figure 3) of Nicksaurus razashahi [17] [18] [19]. Recently this north Kinwa skeleton including cranial and postcranial remains was referred to Saraikimasoom vitakri [22] due to following 
reason. The Saraikimasoom vitakri holotypic teeth from south Kinwa skull MSM-142-4 and Saraikimasoom vitakri referred 6 associated teeth with partial jaw MSM-138-4n from north Kinwa 4n overlapped and have the same morphology, while the non-overlapping portion (postcrania) of the skeleton of north Kinwa $4 \mathrm{n}$ broaden the diagnosis of the species and its distinction from the other Cretaceous titanosaurs of Indo-Pakistan landmass like Isisaurus colberti and Pakisaurus balochistani slender titanosaurs and Gspsaurus pakistani stocky titanosaur. Further the referred materials from north Kinwa 4n (Figure 3) were considered associated due to finding from same locality (within less than $10 \mathrm{~m} \mathrm{dia}$ ) and same formation, fit and same size and no duplication. The femur head was exposed and remaining portion of femur was excavated from the shale of host Vitakri Formation. Further these bones are consistent with other type series and possibly associations of bones of this taxa like Sangiali 1, Mari Bohri 15, lower Bor 2, south Zubra Basti Nala 7 and Grut 9 localities. The Saraikimasoom vitakri bones can be differentiated from other 3 recognized taxa from Indo-Pakistan like Pakisaurus balochistani and Isisaurus colberti slender titanosaurs and Gspsaurus pakistani stocky titanosaur.

Saraikimasoom vitakri remains from Mari Bohri 15 (Figure 7) (Figure 8) were found at the same time on same formation and same locality, so these fossils assigned as holotype postcranial skeleton of Balochisaurus malkani. Balochisaurus malkani was established on caudal vertebrae [14]. Later on some postcranial materials (Figure 7) (Figure 8) found at the same time on same formation and same locality (with same size) added as holotype [44]. So the Balochisaurus malkani holotypic complete fossils are represented in (Figure 7) (Figure 8). Further due to recent work this holotypic vertebral and appendicular elements of Balochisaurus malkani (Figure 7) (Figure 8) are being referred to Gspsaurus pakistani due to caudal vertebrae overlapping and same features.

Saraikimasoom vitakri remains from mid Sangiali 1 [45] belonged to 3 animals of this species. If repeated two humeri and one cervicodorsal put aside, the remaining all materials seems to be associated as one skeleton of Saraikimasoom vitakri. Further the referred materials (except two humeri and one cervicodorsal) from mid Sangiali 1 (Figures 4-6) were considered associated due to finding from same locality and same formation, fit and same size. Further these bones are consistent with other associations of bones of this taxa and other 3 recognized taxa from Indo-Pakistan.

Saraikimasoom vitakri exemplar of South Zubra (Figure 9) based on the morphology of holotypic and referred caudal vertebrae as overlap and used the non-overlapping portion broaden the diagnosis of the species and its distinction from the other Cretaceous titanosaurs of Indo-Pakistan landmass. Please see detail in description.

Here Saraikimasoom vitakri exemplar of Grut Gambrak (Figure 6) based on the morphology of holotypic and referred caudal vertebrae and stocky tibia as overlap and used the non-overlapping portion broaden the diagnosis of the spe- 
cies and its distinction from the other Cretaceous titanosaurs of Indo-Pakistan landmass. Please see detail in description.

Saraikimasoom vitakri referred material from south Kinwa 4 and mid Kinwa 4 $\mathrm{m}$ (Figure 3) based on the morphology of referred vertebral elements as overlap with the north Kinwa, Mari Bohri, South Zubra Basti Nala and Grut exemplars of Saraikimasoom vitakri, and used the non-overlapping portion of remains to broaden the diagnosis of the species and its distinction from the other Cretaceous titanosaurs of Indo-Pakistan landmass.

Saraikimasoom vitakri referred braincase and vertebral materials from Topkinwa (Figure 9) based on the morphology of vertebra. Further braincase is referred to Saraikimasoom vitakri due to $\mathrm{W}$-shaped basioccipital condyle resemblance with Gspsaurus pakistani braincase and differentiated from large braincase of Pakisaurus braincase. Further the size of Saraikimasoom braincase is relatively small while the Gspsaurus braincase is large.

Further a distal neural spine MSM-5/02 Karkh (Figure 9) (first bone from Kirthar basin/lower Indus basin) is also tentatively being referred to Saraikimasoom vitakri. Saraikimasoom vitakri exemplar (Figure 9) of Grut Gambrak based on the morphology of holotypic and referred dorsal and caudal vertebrae, femora and distal stocky tibia as overlap and used the non-overlapping portion broaden the diagnosis of the species and its distinction from the other Cretaceous titanosaurs of Indo-Pakistan landmass. Please see detail in description. Shalghara 3 locality (Figure 9) yielded distalmost trispinous caudal vertebra. Karkk locality, Khuzdar district (Kirthar or lower Indus Range) yielded a distal rib of dorsal vertebra (Figure 9) tentatively assigned to Saraikimasoom vitakri titanosaur, and collected from Karkh locality of Khuzdar district, Kirthar (lower Indus) basin.

The host horizon of these holotypic and referred specimens is the Latest Cretaceous Vitakri Formation [46] [47] of Fort Munro Group from Pakistan and Lameta Formation from India. The genus Saraikimasoom named after Saraiki language of the area and adjoining south Punjab province; masoom is Urdu and Saraiki word meaning innocent. The species name $S$. vitakri named after the host Vitakri area and Vitakri Formation, Barkhan district, Balochistan, Pakistan.

\subsection{Diagnosis of Saraikimasoom vitakri}

Saraikimasoom vitakri diagnosed as small skull located on long neck, round and massive body, short and stocky legs and broad tail. It host thick subsquare proximal tibia. The name-bearing and referred materials of Saraikimasoom vitakri are diagnostic and stable, which provides best cranial, axial and appendicular materials and characters dataset for phylogenetic and systematic studies. Saraikimasoom vitakri is a small sized stocky sauropod dinosaur sharing with the Titanosauria as vertebrae lacking hyposphene-hypantrum articulations, procoelous caudals (except first biconvex caudal), forward insertion of neural arches on caudals, prominent olecranon process on ulna, and anterior dorsal neural 
spines single (not bifurcated).

The Saraikimasoom vitakri shares with most derived forms poripuchian [31] [47] titanosaurs as anterior, middle and posterior caudals found procoelous (except first biconvex caudal). Poripuchia have all especially distal caudals as procoelous [31] [47], while in lithostrotian distal caudals are not procoelous. Poripuchia is the most inclusive clade of Titanosauria containing Pakisaurus and Isisaurus pakisaurids, and Gspsaurus and Saraikimasoom gspsaurids titanosaurs. Poripuch is the Saraiki language word means full tail (with procoelous vertebrae).

The Saraikimasoom vitakri shares with the Gspsauridae (small to medium sized stocky titanosaurs) as U-shaped anterior teeth row and jaw profile, anterior dentary rounded (no chin forming), highly vascularised and pneumatic rostrum and dentaries bones, broad reversed V-shaped palatal, V-shaped dorsal palatal hook attached on the contact of maxilla and premaxilla, slender and circular to slightly oval teeth with slender indices $3-5$, teeth converge and taper on all sides gradually toward tip (opposite of pakisaurids teeth which have almost same thickness except tip), ratio of mid transverse width above and below of mid caudal centrum varies from 1 to 2 with ventral view of mid caudal centra are strongly compressed, proximal subcircular and distal transversely broad stocky tibia (unlike slender tibia of Pakisauridae) and mosaic type and large ellipsoidal osteoderms.

Saraikimasoominae is the most inclusive clade containing Saraikimasoom vitakri but not Gspsaurus pakistani, with characters same as genus and species $\mathrm{Sa}$ raikimasoom vitakri. Saraikimasoominae major differentiation features from Gspsaurinae are as U-shaped anterior dentaries symphyses profile, dentary symphysis orientation is perpendicular to axis of jaw ramus, relatively small sized skull (than Gspsaurinae), relatively small but more robust teeth (than Gspsaurinae), straight to recurved and circular to slightly oval conical and pointed teeth with gradually decreasing diameter toward tip, relatively small size (in thickness, width and length) dentaries rami (than Gspsaurinae), ventral view of mid caudal centra are strongly reduced/compressed with the ratio of mid transverse width above and below varies from 1.5 to 2 and circular to subcircular stockier tibia (than Gspsaurinae).

Saraikimasoom vitakri autapomorphies are very small sized spongy snout with dorsal profile inclined moderately or $40^{\circ}$ from horizontal; relatively short, broad and less deep skull without anterior step; low angle less than $25^{\circ}$ pterygoid or palatine process (while Gspsaurus have about $45^{\circ}$ pterygoid or palatine process); premaxillary canal is reversely triangular and high angled $\mathrm{V}$ shaped; teeth converge and taper gradually from base of crown to tip (while teeth of Pakisaurus and Rapetosaurus have constant thickness of teeth from base to tip); teeth are small, circular to subcircular, slightly recurved and rounded and pointed tips; teeth with slender indices vary from 3 - 5 (while Pakisaurus and Rapetosaurus have teeth with Slender Indices more than 5): upper and lower U shaped teeth 
rows (while Gspsaurus have upper U-shaped and lower V-shaped teeth rows); dentary ramus anterior depth is slightly more than dentary at mid length (while dentary ramus anterior depth of Gspsaurus is less than dentary at mid length): dentary with narrow anteroposteriorly symphysis (while Gspsaurus have long anteroposteriorly symphysis); anterior dentary rounded (no chin or very small chin); dentary symphysis, perpendicular to axis of jaw ramus (while in Gspsaurus it is an extension and not perpendular); dental formula 4, 13/9 - 13; small braincase with subrectangle shaped occipital condyle with sagital groove (while the Pakisaurus and probably Isisaurus have D-shaped occipital condyle and Gspsaurus have rectangle shaped occipital condyle); braincase has a prominent supraoccipital wedge and proatlantal facets; first caudal is biconvex and broad with relatively more long than Gspsaurus, ventrally reduced broad caudals (while Pakisaurus and Isisaurus have not ventrally reduced caudals, however in Gspsaurus ventral reduction ratio is less than 1.5); trirays procoelous distalmost caudal (while Pakisaurus have horizontal groove in the mid of distalmost caudal); transversely thick and expanded distal scapula; medially inset deltopectoral crest in proximal humerus; anteriorly exposed and expanded radial condyle of distal humerus (while Isisaurus have no expanded radial condyle); gracile ulna with long trirays; rectangle or subrectangle shaped cross section of shaft just below the femur head; subsquare shaped proximal tibia with equal anteroposterior and transverse width, and transversely quite broad distal tibia; very close articulation of proximal fibula and proximal tibia; proximal fibula orientation shifted the trend of proximal fibula from anteroposterior to almost mediolateral due to transversely expanded fibular condyle of proximal tibia (instead of anteroposterior or anteromedial to posterolateral orientation as in Pakisaurus and Isisaurus) when articulated with proximal tibia; osteoderms two types, the first small suboval or subrectangular mosaic type thick plate (more thick than the Gspsaurus mosaic plate) and secondly the large subcircular ellipsoidal plate without median cut or groove (while Gspsaurus and Malawisaurus both have large oval ellipsoidal plate with median goove or cut).

\subsection{Description of Fossils of Saraikimasoom vitakri}

\section{Cranial fossils}

Previously no any snout of titanosaur from Indo-Pakistan subcontinent is reported but due to recent discoveries from Pakistan, the Saraikimasoom and Gspsaurus represented by snouts which provide the facility for comparisons at global level. The Gspsaurus is based on skeleton which is represented by snout and associated braincase and postcranial vertebral and appendicular and limb elements, which provide the facility for the phylogenetic and systematic studies. Further the Saraikimasoom holotypic snout and referred skeletons of north Kinwa, Mari Bohri and possibly mid Sangiali exemplars which are represented by cranial and postcranial materials along with key elements. Both Gspsaurus the medium sized stocky titanosaur and Saraikimasoom the small sized stocky 
titanosaur provide the facility for the phylogenetic and systematic studies.

Snout with articulated teeth: The holotypic snout MSM-142-4 (Figure 1) (Figure 2) collected from few ten meters toward south from south Kinwa peak, located just west of Kinwa spring locality, and referred cranial materials six teeth in jaw ramus MSM-138-4n, skull and teeth fragments in matrix MSM-315-4n and MSM-314-4n collected along with associated postcrania of Saraikimasoom vitakri from north Kinwa locality. The Saraikimasoom vitakri teeth length and width are two third to nearly half of the Gspsaurus pakistani. So Saraikimasoom vitakri is a small size form and Gspsaurus pakistani is a medium size form. This snout represents generally long, narrow and moderate shallow shape (with $40^{\circ}$ inclinations from horizontal). The external nares position is not terminal and seems to be retracted back but at what level further position unknown. The exposed part of dentary rami is pneumatic with large open internal cells, showing this rostrum and partial skull is highly vascularised. The anterior portions of upper jaws are broadly arched forming U shape. The shape of premaxillary anterior margin is without step. Teeth are slightly recurved, circular to oval, long and slender, with rounded and pointed tips. The fellow of premaxilla meets with each other by a dominant mid contact. At midline contact it forms a slight elevated or ridge forming thin belt. The shape of premaxillary anterior margin is without step. There are 4 premaxillary teeth. The premaxilla strip has transversely slightly more width at anterior extremity. The premaxillary teeth vary from 0.5 to $1 \mathrm{~cm}$ (centimeter) in length and vary 0.2 to $0.4 \mathrm{~cm}$ in diameter. The premaxillary teeth can be observed only on the anterolateral aspect of left side of anterior rostrum. Left side of snout/rostrum is better preserved while right side of rostrum is mostly weathered/eroded, and covered by red to maroon muddy matrix. The upper jaw teeth cover the left dentary ramus. It is interesting to mention that the both snouts of Saraikimasoom vitakri and Gspsaurus pakistani include dentary rami covered by upper jaw teeth. In Saraikimasoom vitakri rostrum, the dentary teeth are exposed on the right side due to the partial erosion of the right side maxilla. Premaxilla formed transversely narrow main body that is greatly elongated rostrocaudally as strip or belt like. Laterally it has a long contact with maxilla. Its each preserved fellow is $8.5 \mathrm{~cm}$ long, and $1 \mathrm{~cm}$ wide on each side measured at the cross section just behind the ending of teeth row. The both fellow are about $2 \mathrm{~cm}$ transverse wide. It goes backward with about $40^{\circ}$ inclinations from the anterior most point of premaxilla. The contact of premaxilla and maxilla is clear and observed on the anteriormost of the snout and on the backside of cross sectional area, but laterally and dorsally it is covered by red brown matrix. The shape of anterior portions of premaxillary and maxillary tooth rows is broadly arched U-shape (Figure 1) (Figure 2).

In Maxilla, there are two major parts, a horizontal tooth bearing lateral/posteroventral process and a prominent dorsal ascending process. The maxilla is a triangular element from lateral view. Its dorsal process and also lateral process bifurcate at the start of antorbital fenestra. The antorbital fenestra is starting at 
about $8 \mathrm{~cm}$ length from anterior most premaxilla junction. The antorbital fenestra is more than $3 \mathrm{~cm}$ dorsoventral height after a $2 \mathrm{~cm}$ start. The antorbital fenestra started at the ending of maxillary teeth row. The teeth have little gap less than $2 \mathrm{~mm}$ among each other. The larger teeth are observed in the middle of teeth row i.e. the fifth and sixth maxillary teeth. However distal parts of the most of the teeth are eroded. The maxillary teeth vary from 1 to $1.5 \mathrm{~cm}$ in length and 3 $-4 \mathrm{~cm}$ in diameter. The length and width of longest maxillary teeth is about 1.5 $\mathrm{cm}$ and $0.4 \mathrm{~cm}$ respectively. The smallest teeth are less than $1 \mathrm{~cm}$ especially in the posterior part of row. Some teeth have rounded tips and some have pointed tips. However the exposed dentary teeth vary from 1 to $1.2 \mathrm{~cm}$ in length and width $3-5 \mathrm{~cm}$. There are 13 maxillary teeth. The maxillary teeth bearing part is $7 \mathrm{~cm}$ long and preserved backward portion without teeth is $4.5 \mathrm{~cm}$. Backward to teeth row the upper jaw showing concavity and the lower jaw showing upward convexity, an indication of coronoid process. There are anteroposteriorly oriented parallel lamination on the maxilla and premaxilla (Figure 1) (Figure 2).

The Palatal is curved which is mostly covered and filled by muddy matrix, however on the upper part, the dorsal palatal processes are bifurcated forming cavity and connected with the premaxillary-maxillary contact. The dorsal palatal processes form a $\mathrm{V}$-shaped hook type bone which support ventral palatal process or pterygoid/palatine. The ventral palatal processes are also bifurcated and trended towards lowermost portion of maxilla. The left and right palatal processes are mirror images with each other but tilted due to overall tilting of rostrum. The dorsal and ventral processes are convergent with each other only in the median part. On dorsal aspects each fellow of dorsal palatal process contacted at the respective suture of maxilla and premaxilla. The dorsal palatal processes converged ventrally at mid portion of rostrum. At this junction the ventral palatal processes also converge to form a double junction. From this double junction the left and right lateral processes of ventral palatal started diverging and meet at respective maxilla. The ventral palatal processes form broad and reversed V-shape mehrab (arc convexing dorsally). The ventral most part of palatal is forming vaulted and dorsally convexing arc. Pterygoid flange is more than $4 \mathrm{~cm}$ wide, and thickness is about $1 \mathrm{~cm}$. The wing of pterygoid contacts is opposite elements in broadsheet. Pterygoids flanges meet with each other at gentle angle from horizontal. Palatal shelf on maxilla is between the ventral palatal process and dorsal palatal process form maxillary canals-left and right maxillary canals. Palatal shelf is just below the left and right premaxillae and above the dorsal palatal processes form one premaxillary canal. The premaxillary canal is dorsally enclosed by both fellow of premaxillae and ventrally and laterally enclosed by dorsal palatal processes. Premaxillary canal is reverse triangular and high angled V shaped (Figure 1) (Figure 2).

The preserved left dentary ramus length is about $8-9 \mathrm{~cm}$. The dentary ramus dorsoventral height varies from 1.25 to $1.5 \mathrm{~cm}$ and transverse thickness is about 
$0.5 \mathrm{~cm}$. The dentary ramus dorsoventral height is less at the mid length which is about $1.25 \mathrm{~cm}$, and slightly increasing anteriorly and also posteriorly upto 1.5 $\mathrm{cm}$. However the exposed dentary teeth vary from 1 to $1.2 \mathrm{~cm}$ in length and width $3-4 \mathrm{~cm}$. At the level of angular/surangular total dorsoventral height of ramus is about $2 \mathrm{~cm}$. The lateral and anterolateral views of left dentary are partially exposed. The right dentary is mostly not exposed and covered by mud and only right dentary three teeth are exposed after the damage of right maxilla. The dentary is shallow, thin/narrow and also small. Articulated dentaries or dentary symphysis represents $\mathrm{U}$-shaped curvature. The anterior portion of each dentary ramus curving gently is towards the anterior midline. The curvature of the dentary toward the midline begins at the level of its slight increasing vertical depth (at approximately the third or fourth dentary alveolus). The dorsoventral axis of the vertical symphysial surface slightly less than 90 degree or close to perpendicular to the long axis of the dentary, and is triangular in medial view with a narrow ventral apex and broad dorsal base. The dentary is slightly dorsoventrally expanded anteriorly, but damage occurred to this ventral margin. The dentary and postdentary elements provide an estimated lower jaw length of $18-20 \mathrm{~cm}$. Postdentary bones extend $5-8 \mathrm{~cm}$ posterior to the dentary. Based on the associated lower jaw elements, the Saraikimasoom skull is estimated at approximately about $20 \mathrm{~cm}$ in length. In right lateral view, the feeble indication of neurovascular foramina is positioned below each alveolus. At mid length the dentary ramus is minimum deep while anteriorly it deepens or increasing slightly and posteriorly when angular and surangular started its depth slightly increased than mid dentary. The posterior portion of the dentary is divided into distinct dorsal and ventral rami, immediately behind the possible last teeth or last alveolus. The dorsal ramus is for the reception of the surangular and ventral ramus the reception of the angular. The distal end of the dorsal and ventral rami is broken. The deep posterior emargination formed by the diverging rami is covered laterally by the large surangular (Figure 1) (Figure 2).

The depth of Dentary ramus is nearly sub equal and anteroventral margin shape is not chin forming. Angle between long axis of mandibular symphysis and long axis of mandible seems to be almost perpendicular. The anterior portions of dentary are broadly arched forming $U$ shape. The dentary ramus along with preserved possibly surangular measurement is $8 \mathrm{~cm}$. The best preserved impressions of three teeth of right dentary are found. The impression of central tooth (among these three teeth) is about $1.5 \mathrm{~cm}$ long, and $0.5 \mathrm{~cm}$ wide. These teeth are exposed due to partial erosion of right maxilla and premaxilla. Tooth crowns do not overlap. The Surangular at the anterior portion is interpreted due to coronoid process i.e. the convexing upward, and the upper jaw is concaving when teeth row is finishing. Convexing and concaving occur parallel with each other for accommodation of relevant contacting elements. The concavity of upper jaw may also be consistent with the anterior process of possible quadratojugal. 
The length of teeth is going to be increased from saggital symphysis or midline to centre of row and then decreasing up to end. The anterior and posterior of teeth row indicate relatively small teeth than the mid row and at the anterior maxillary row. The anterior maxillary teeth are longest and robust than premaxillary and posterior maxillary teeth. Same image can be seen in dentary teeth. The middle of dentary teeth is robust and longer than the anterior and posterior dentary. Longer teeth preserved in the middle of upper jaw or maxilla seem like $3^{\text {rd }}$ to $6^{\text {th }}$ maxillary teeth and also dentary teeth are longer facing to or close to $3^{\text {rd }}$ to $6^{\text {th }}$ maxillary teeth. Some teeth are pointed and cone forming, some are rounded and some show wear facet. So the Saraikimasoom represents cylindrical to rounded teeth with gradually decreasing diameter upto tip. Teeth seem to be recurved. Tooth crown cross-sectional shape at mid crown is subcircular to circular. The tooth slenderness varies from 3 - 4. The premaxillary and maxillary teeth covered the lateral side of dentary ramus showing relatively less transverse diameter than the lower jaws. The lower jaw teeth are more robust than upper jaw teeth. Teeth are long, circular to oval, narrow and slender. The upper jaw has teeth 17 (with premaxillary 4 and maxillary 13 teeth), while dentary expected 11 - 13 teeth but the exposed teeth on right dentary show width of teeth is greater which represent less teeth count than upper jaw. In this way Saraikimasoom vitakri represents possible dental formula 4, 13/11 - 13 (Figure 1) (Figure 2). The teeth row of left upper jaw seems to be complete and it gives the best information for the more derived Titanosauria in globe. Traditionally, titanosaurids were considered as Diplodocus-type skull [33] but Pakistan yielded moderate long skull with moderate inclination.

Rapetosaurus [34], Nemegtosaurus (ZPALMgD-I/9 [48]), Quaesitosaurus (PIN 3906/2 [49]) and Gspsaurus (MSM-79-19 [23]) have robust dentaries that are dorsoventrally expanded posteriorly and anteriorly but Saraikimasoom has very shallow, slender and small dentaries that is dorsoventrally slightly expanded posteriorly and anteriorly. When compared to Saraikimasoom, Malawisaurus (SMU MAL 174 [50]) has a relatively shallow dentary without significant posterior expansion. Comparison of the dentary of Saraikimasoom, with that of the titanosaurs Rapetosaurus [34], Ampelosaurus MD-E C3-336 [51]), Nemegtosaurus (ZPAL MgD-I/9 [48]), and Quaesitosaurus (PIN 3906/2 [49]) revealed overall close similarities in the number of teeth, the position of teeth, and the orientation of the mandibular symphysis. In each of these taxa (as well as in Brachiosaurus and Camarasaurus), minimum tooth counts range from 9 ( $\mathrm{Am}$ pelosaurus MD-E C3-336 [51]) to 15 (Malawisaurus [50]) while in Saraikimasoom tooth counts approaches upto 17 . All of these taxa exhibit a gently curving dentary that meets in a broad, U-shaped symphyseal region. Similarly, in all but Nemegtosaurus (ZPAL MgD-I/9), alveoli are present along $60 \%-80 \%$ of the dorsal margin of the dentary. The restriction of the alveoli to the anterior $2 / 3$ of the dentary also distinguishes Saraikimasoom and other titanosaurs from diplodocoid taxa in which the tooth row is restricted to the anterior one-third of the 
dentary.

Saraikimasoom teeth are generally similar to the teeth of Rapetosaurus [34], Nemegtosaurus (ZPAL MgD-I/9 [48]) and Quaesitosaurus (PIN 3906/2 [49]) in diameter and overall shape. Tooth Slenderness Indices (length of crown divided by maximum mesiodistal width [35]) in Saraikimasoom vary from 3 - 5, while this ratio exceed 5.0 in other titanosaurs including Rapetosaurus [34], Ampelosaurus, MDE C3-336 [51]; Malawisaurus, SMU MAL-6, 174 [50]; Nemegtosaurus, ZPAL MgD-I/9 [48]; Quaesitosaurus, PIN 3906/2 [49]. The teeth of Saraikimasoom are small to moderately large and mostly tapering gradually from base to tip while tooth from India [52] which has almost same thickness except reduced tip.

Like Rapetosaurus, the cranial and postcranial material of Saraikimasoom is among the most complete and best preserved of any described titanosaur, and yields interesting new insights into overall titanosaur skull and postcranial morphology. The skull of Saraikimasoom and Rapetosaurus are similar to diplodocoids in its overall shape, with retracted external nares and an elongated snout. However, tooth distribution throughout the upper and lower jaws is more similar to those of macronarians like Camarasaurus and Brachiosaurus. The maxilla, teeth, dentary, dentary symphysis, palatal process, and basioccipital condyle are among the most diagnostic elements of the Saraikimasoom skull, along with the enlarged and anteriorly oriented antorbital fenestra.

Due to the dearth of cranial data for other known titanosaurs especially most derived titanosaurs, the Saraikimasoom, Gspsaurus and Rapetosaurus have great potential to clarify higher and lower level titanosaur phylogeny.

Saraikimasoom has plate like pterygoid like the pterygoids of Nemegtosaurus (ZPAL MgD-I/9 [48]), Quaesitosaurus (PIN 3906/2 [49]), Rapetosaurus [34], and Gspsaurus [23]. Saraikimasoom pterygoids meet at an angle of less than $25^{\circ}$ like Nemegtosaurus. While Gspsaurus and Rapetosaurus pterygoids meet at an angle of about $45^{\circ}$, in contrast to the $25^{\circ}$ convergence in Saraikimasoom and Nemegtosaurus. The Saraikimasoom has pterygoid V-shaped hook like Gspsaurus. The Saraikimasoom has pterygoid V-shaped hook but Rapetosaurus, Nemegtosaurus, Quaesitosaurus, and Brachiosaurus have no pterygoid hook. Among sauropods, Saraikimasoom (MSM-42-4) and Gspsaurus (MSM-79-19, MSM-80-19) uniquely share the dorsal palatal process (=pterygoid hook) and provide the cross sectional view. Saraikimasoom (MSM-42-4) has dorsal palatal process (=pterygoid hook) observed at cross sectional view just back of end of teeth row or at the surangular foramen showing the cross sections of dentaries, maxillae, premaxillae, palatine/pterygoid, ectopterygoid, dorsal wing of pterygoid, suture of dorsal wings of pterygoid forming vaulted roof or raced roof, dorsal palatal $\mathrm{V}$-shaped hook and their junctions. Further it provides unique structures at the posterior cross section.

Braincase: The Saraikimasoom vitakri braincase (GSP/MSM-2-16 and GSP-UM 7000) (Figure 9) along with associated its postcranial fossil remains were dis- 
covered by Malkani from the Top Kinwa locality, just on the eastern extremity or peak of Kinwa stream (Figure 9). This braincase is reported by [53] and most description of Saraikimasoom vitakri braincase is taken and modified from them. The Saraikimasoom vitakri braincase is well preserved and relatively small. Its tight fused suture, and vertebral and limb elements suggest a mature and single individual. The parietal is a paired with fused and traceable midline element that contacts the frontal anteriorly, and the supraoccipital, exoccipital-opisthotic, prootic, and laterosphenoid bones ventrally. The parietal is exposed on the dorsal and posterior surfaces of the skull. The supratemporal fenestra is not preserved. The parietal and frontal seem to be tightly sutured with roughened line traversing the dorsal skull probably represents their contact, while in other sauropods, the frontal-parietal contact is positioned near the contact of the laterosphenoid and prootic, and it coincides with a diminution of skull roof thickness that can be observed in lateral view. A shallow depression along the frontal-parietal suture, most pronounced on the right side, may represent part of the fossa surrounding the supratemporal fenestrae. The posterior margin of the skull is marked by low, arcuate ridges formed by the parietal on either side of the supraoccipital. The parietal is well exposed in posterior view, where it wraps over the supraoccipital wedge and extends laterally to overlay the exoccipital-opisthotic. The frontal, like the parietal, is a paired midline element and it is little preserved. An available cross-section near the midline anteriorly reveals a thickness of about 3 millimeters. The frontal increases to nearly twice this thickness at its preserved lateral extreme. The frontal contacts the laterosphenoid along a transverse contact that is visible on the left side. In dorsal view, the frontal forms part of the shallow supratemporal fossa. The supraoccipital is the median basicranial element above the foramen magnum. It contacts the parietal dorsally and the exoccipital-opisthotic laterally and ventrally. Its suture with the exoccipital-opisthotic is not visible, but the supraoccipital likely contributed to the margin of the foramen magnum, as it does in other sauropods. The supraoccipital is slightly taller than the foramen magnum and bears a prominent wedge that extends noticeably from the plane of the occiput, as seen in lateral view. The prominence of the supraoccipital wedge, which is not complete, may be diagnostic.

The basioccipital is the median element that forms most of the occipital condyle and the ventral margin of the foramen magnum. Its contact with the exoccipital-opisthotic dorsally is tightly sutured, as is its contact with the basisphenoid anteriorly. The occipital condyle is generally D-shaped, with a flattened dorsal surface and a hemispherical posterior surface with base may be feebly represented by $\mathrm{W}$-shaped i.e. the ventroposteriorly occipital condyle showing a small groove or depression making feeble $\mathrm{W}$-shaped, a diagnostic feature. A shallow groove on the left side of the occipital condyle suggests that the exoccipital-opisthotic formed its dorsolateral corner. A single opening for cranial nerve XII pierces the neck of the occipital condyle; it is likely that this opening passed 
through the basioccipital, rather than through the exoccipital-opisthotic or between the two. The occipital condyle is strongly deflected ventrally and forms an angle of approximately 120 degrees with the skull roof. This deflection is not preservational and may be a diagnostic feature. The basioccipital and basisphenoid form the basal tubera, which are incomplete. The basioccipital forms the posterior margin of the metotic foramen; a trace of its suture with the basisphenoid is visible in the floor of this opening. The basisphenoid is the median element that forms the posterior portion of the braincase floor. It contacts the basioccipital posteriorly and the prootic, laterosphenoid, and orbitosphenoid dorsally. The basisphenoid is incomplete ventrally and anteriorly. The basioccipital forms the anterior margin of the metotic foramen as well as the floor of the openings for cranial nerves III and V. A small opening on the left side of the braincase may represent the opening for cranial nerve VII or VI, but the corresponding region is damaged on the right side. The exoccipital-opisthotic forms the lateral margins of the foramen magnum, the shoulders of the occipital condyle, and the paroccipital processes. It contacts the parietal, supraoccipital, prootic, basioccipital, and basisphenoid. Paroccipital processes are not completely preserved; the preserved portion suggests that they were arched ventrally. Two rounded prominences on either side of the foramen magnum are facets for articulation with the proatlas. Proatlantal facets are uncommon in sauropods and may be diagnostic.

The prootic is a large, paired basicranial element that forms the anterior surface of the paroccipital processes. The prootic of Saraikimasoom vitakri lacks only its distal end. It contacts the laterosphenoid anteriorly, the exoccipital-opisthotic posteriorly, the parietal and possibly the frontal dorsally, and the basisphenoid ventrally. The prootic forms the forms the anterodorsal margin of the metotic foramen and the posterior margin of the trigeminal foramen. The fenestra ovalis opens is positioned between these openings. The laterosphenoid is a transversely oriented paired braincase element that forms part of the wall of the endocranium and separates the supratemporal and orbital regions of the skull. The laterosphenoid is partially preserved, lacking its distal head and anterodorsal margin. It contacts the frontal and parietal dorsally, orbitosphenoid anteroventrally, and the basisphenoid ventrally. The laterosphenoid contribution to the dorsal margin of the openings for cranial nerves $\mathrm{V}$ and III is preserved, but its contribution to the opening for cranial nerve IV is not. Cranial nerve foramina V, III, and II are aligned with one another and oriented parallel to the skull roof. The paired orbitosphenoids enclose the anterior portion of the endocranial cavity. Only the posteriormost portion of the orbitosphenoid is preserved, extending forward from its contacts with the basisphenoid and laterosphenoid near the opening cranial nerve III to the posterior margin of cranial nerve II.

This braincase is relatively small size, slight median groove/cut (constricted dorsoventral median groove) on posterior view of basioccipital condyles forming 
W-shaped lower and reverse W-shaped upper views, the lateral side of basioccipital condyle is convex like other Indian titanosaur braincases, braincase have a prominent supraoccipital wedge, pronounced proatlantal facets, and a ventrally deflected occipital condyle that forms a $120^{\circ}$ angle with the skull roof.

The reference [53] mentioned that both the Pab braincase and the Dongargaon braincase were found at localities preserving postcranial remains of the titanosaur Isisaurus, the present investigation shows no any postcranial remains of Isisaurus found from Topkinwa. This locality presented skeleton of Gspsaurus, some bones of Saraikimasoom and some bones of Pakisaurus. The reference [53] mentioned that although further associations are required. The presently associations from Pakistan and India [23] [24] and reported here revealed that the Pab braincase belongs to Saraikimasoom and this result is consistent with the other cranial and postcranial assignment. The other Indian sauropod genus, Jainosaurus, is represented by braincase material that has been recovered only from central and western India. Postcranial remains attributed to Jainosaurus are not diagnostic [53]. But the present finding represented diagnostic cranial and postcranial materials of recognized four titanosaur taxa from Indo-Pakistan.

\section{Vertebrae}

Cervical vertebrae: A few cervical vertebrae (Figure 3) (Figure 4) (Figure 7) were found. The Cervical centra are broad, long, opisthocoelous, pneumatic and have almost flat and slightly concave ventral surface because anterior cone and posterior articular surfaces are trending to lower level than central surface of centra. The Cervical ribs are broad V shape and pneumatic. Cervical ribs have angle slightly more than $90^{\circ}$. The centra have long pleurocoel.

Cervicodorsal vertebrae: There are two cervicodorsal vertebrae collected from mid Sangiali (Figure 4). Parapophyses are located on the anterior of pleurocoel. Centra are broad and short i.e. height is less than width. The length is more than width. The centra are strongly opisthotic. One vertebra has double pleurocoel or divided pleurocoel by bony septa. The other vertebrae have single pleurocoel and ventral flat surface. The broken vertebrae represent the spongy/pneumatic texture.

Dorsal vertebrae: The dorsal centra (Figure 4) (Figure 7) are opisthocoelous, broad (proximal and distal dorsals) to slightly tall or subcircular (mid dorsals) pneumatic and have long and deep pleurocoel with thick lip. There is no hyposphene-hypantrum articulation in any of the collected dorsals. Dorsal neural spine is not bifid. Proximal bifurcated process of rib joins to form one wide rib strip which is pneumatic but at the distal ends it becomes compact and node type. Presacral neural spine is spongy. Deep slit like pleurocoels occur on the lateral surfaces just below the neural arches on the slightly tall centra. The spine is inclined backward.

A few thoracic rib pieces are collected. The tuberculum and capitulum are of subequal size, subrounded capitulum and oval to suboval toberculum and are marked with a notch in between. There is a marked ridge running along the length 
of the rib shaft bifurcating just before the proximal notch and terminating toward the end of the capitulum and tuberculum. Medially there is a marked depression running anteriorly. The proximal part of the rib is spongy and concavo-convex in cross section and distally massive and plano-convex.

Caudal vertebrae: All the caudal vertebrae are strongly procoelous (Figure 4) (Figure 7) (Figure 9), except first biconvex caudal (Figure 7) The anteriormost or first caudal centrum is biconvex, heavy, broad, and elongate, in this regard gspsaurids of Indo-Pakistan subcontinent matches with Pellegrinisaurus from Patagonia, Argentina and Neuquensaurus from Argentina, South America, and Alamosaurus from USA, North America. This feature shows southern and also northern hemisphere distribution of this feature. The reference [54] mentioned biconvex first caudal in Neuquensaurus from South America while [55] mention procoelous first caudal feature in Neuquensaurus. The centrum is not biconvex in Paralititan from Egypt, Africa, as in the titanosaurids Alamosaurus from USA, Neuquensaurus and Pellegrinisaurus from Argentina [56]. The morphology of Gspsaurus first caudal centrum which is ball like heavy biconvex but here the Saraikimasoom first caudal is broad, elongate and biconvex. Anterior caudals are broad while the mid caudals are broad to squarish and posterior caudals are cylindrical with prominent anterior circular articular with ball having highlighted cone set dorsally and posterior circular posterior articular region. Both the height and width of caudal centra reduces much backward with relative to their length, which reduces less. The chevron facets are not found on the anterior most caudals and posterior caudals, while located in the remaining anterior and middle caudals. The neural arch is situated on the anterior half of the caudal centra. The prezygapophyses are rod like while post zygapophyses also have lateral small surface for attachment. Prominent rib facets (transverse processes) occur which seems like tapering in anterior caudals. Saraikimasoom vitakri represents broad and relatively long first biconvex caudal centrum (Figure 7); short, heavy and narrow well developed ventral groove due to well developed anterior and posterior chevron facets of anterior caudals (may be except anteriormost caudals) and mid caudal (ventral grove is $\mathrm{V}$ shaped); the ratio of mid-dorsal width to mid-ventral width of anterior caudals (may be except anteriormost caudals) and mid caudals ratio varies 1.5 to 2 or more; lateral surfaces on ventral view are clearly observed in the anterior and mid caudals due to mid-dorsal width highly greater than ventral width and forward insertion of robust neural arch. Anterior and middle caudal neural spine is transversely wide blade type spine with prezygapophyses and postzygapophysis i.e. the anterior caudal neural spine is anteroposteriorly compressed. The measurements of some caudal vertebra are shown in tables $5 \mathrm{a}$ and $5 \mathrm{~b}$ of [9]. The distal caudals are elongate cylindrical and anteroposteriorly wide and low neural spine (laterally compressed and low). The distal caudals have prominent posterior articular ring and posterior ball is not restricted (unlike restricted in Gspsaurus). Anterior or middle caudal chevron is transversely compressed with deep haemal canal while the 
posterior caudal chevron anteroposteriorly compressed with shallow haemal canal. The posterior caudal chevron arch (above the haemal joint) and chevron spine (below the haemal joint) are anteroposteriorly compressed, however it curved posteriorly at the mid of chevron spine while distal chevron spine is circular (not compressed); and haemal canal is shallow. The compression of chevron blade seems to vary from anterior to distal caudal series.

The trispinous distal caudal centrum (Figure 7) of Saraikimasoom vitakri found from Mari Bohri 15, mid Bor 2 and Shalghara 3 localities which are relatively small size than Gspsaurus pakistani distal caudal centrum. The trispinous distal caudal centrum have anterior coel concavity like other caudals and posteriorly different with two prezygapophyses lies upward and one postzygapophysis lies downward or vise versa, it creates specialty. It has no posterior ball unlike other caudal centrum, so its size, shape and character put these trispinous caudal as caudal cap. In this regards the Gspsaurus pakistani and Saraikimasoom vitakri titanosaurs from Pakistan are unique among World. It seems to be robust and relatively short tail which may act for multipurpose like good defending tool for its foe like Vitakridrinda and Vitakrisaurus theropods, and Pabwehshi, Induszalim, Sulaimanisuchus and Khuzdarcroco mesoeucrocodiles, and balancing body as third support during foraging from tall tree and mating.

As conclusion five types of vertebrae especially caudal vertebrae were collected and diagnosed from Indo-Pakistan. First type, tall mid caudals with ratio of mid transverse width above and below of centrum is about 1 belongs o Pakisaurus, slightly tall mid caudals with ratio of mid transverse width above and below of centrum is about 1.3 to 1.5 , belong to Marisaurus or Gspsaurus, squarish to broad mid caudals with ratio of mid transverse width above and below of centrum is about 1.5 to 2, belong to Balochisaurus or Saraikimasoom; squarish mid caudal with ratio of mid transverse width above and below of centrum is about 1, belong to Isisaurus or Sulaimanisaurus; squarish mid caudal with ratio of mid transverse width above and below of centrum is slightly less than 1, belong to Khetranisaurus [9].

\section{Appendicular and limb elements}

Scapula: The mid scapular MSM-746-7 (Figure 9) from Zubra Basti Nala 7 and partial left scapula GSP/Sangiali 1109-1112 (Figure 5) from Sangiali 1 are found so far. The mid scapula has D shape cross-section and its ventral concave side also have ridge or ventral crest located on medial side. Just above the acromian, the mid scapular blade has slight sharp elongated ridge on the axis of convexity on lateral aspects. The angle from mid to distal blade show that the distal scapula of Saraikimasoom vitakri is not deflected laterodorsally i.e. it is straight or slightly deflected medially (while the scapula of Pakisaurus balochistani and Isisaurus colberti pakisaurids are deflected laterodorsally). The middle part have convexity on dorsal side and concavity in the medial side generally forming D-shape. Mid Scapula have medial tuberosity which is transversely divided or bifurcated. The width of middle part is remarkably less than distal ends 
(the acromial process). Distal scapula is stocky and expanded and represents broadening and thickening at the distal end forming a most deep and spoon shape glenoid for humerus head, and then slight bend and then rugosity on expanded surface for the attachment of coracoid situated and then again a bend happed and after the bend the relatively less expanded acromian situated. Distal scapula and coracoid are separate. Distal scapulae are relatively largest in size. The acromian size seems to be moderate to high and acromial edge is slightly expanded. The distal scapula seems not to be deflected laterodorsally i.e. it is straight or slightly deflected medially like Gspsaurus pakistani, while the distal scapula of Pakisaurus balochistani and Isisaurus colberti pakisaurid is deflected laterodorsally. The distal scapulae of Saraikimasoom vitakri and Gspsaurus pakistani are relatively more stocky (transversely expanded) than Pakisaurus balochistani. The distal scapulae of Saraikimasoom vitakri, Gspsaurus pakistani and Pakisaurus balochistani have relatively short articular surface for coracoid while Isisaurus colberti has relatively long articular surface for coracoid. The Saraikimasoom vitakri distal scapula of Sangiali 1 anteroposterior width is about $33 \mathrm{~cm}$ while depth is $15 \mathrm{~cm}$ which is maximum at glenoid. The stocky ratio width/length of Sangiali 1 exemplar of Saraikimasoom vitakri is about 0.45. The Gspsaurus pakistani distal scapula of Mari Bohri 15 anteroposterior width is $36 \mathrm{~cm}$ while depth is $18 \mathrm{~cm}$ which is maximum at glenoid. The stocky ratio width/length of Mari Bohri exemplar of Gspsaurus pakistani becomes 0.5. The Gspsaurus pakistani distal scapula of Topkinwa 16 anteroposterior width is $25 \mathrm{~cm}$ while depth is $12 \mathrm{~cm}$ which is maximum at glenoid. The stocky ratio width/length of Topkinwa 16 exemplar of Gspsaurus is about 0.48 . The Pakisaurus balochistani distal scapula of Kinw 4, anteroposterior width is $32 \mathrm{~cm}$ while depth is $12.5 \mathrm{~cm}$ which is maximum at glenoid. The stocky ratio width/length become 0.39 for Pakisaurus balochistani. So these ratio of Saraikimasoom vitakri (0.45), Gspsaurus pakistani (0.48 - 0.50), and Pakisaurus balochistani (0.39), show high difference.

Coracoid: A left coracoid GSP/Sangiali 1113 (Figure 5) from Sangiali 1 were found from Pakistan. The coracoid has a rounded, subrectangular outline. The glenoid surface is elongated oval, expanded and curved shaped to fit with glenoid surface of distal scapula for the adjustment of humerus. Its articular surface is rugose and convex to adjust with the distal scapular articular surface which is slightly convex. The scapular facet surface is not expanded and smaller than the glenoid surface. The well developed subcircular coracoids foramen is located below the coracoid scapular facet/articular surface. This coracoid foramen is inside the coracoids plate like the Isisaurus, while the coracoids foramen is on the boarder of plate with the scapula in Rapetosaurus. There is a depression at the anteroventral termination of glenoid surface. Below the glenoid surface, there is a depression in the coracoid plate and then plate bended medially. An infraglenoid lip type feeble ridge is also found.

Sternal Plate: The partial anterolateral sternal MSM-675-15 (Figure 8) is found. Sternal anterolateral edge is thick and subrounded. There are vertical wavy 
rugosities on the anterior, anterolateral, anteromedial of anterior sternal plate. These rugosities show connecting with the scapular coracoid region and other fellow. The plate is slightly concave on the ventral and dorsal sides. The anterolateral thickest part of sternal plate is constricted longitudinally in the central or middle longitudinal line showing behavior as cleavage of upper and lower ridge plates. From this thick corner the thickness is consistently reduced in the medial and posterior side.

Humerus: A humerus (proximal humerus MSM-245-15 and distal humerus MSM-174-15; Figure 8) from Mari Bohri 15, and three proximal right humeri GSP/Sangiali-1114, 1115 and 1116 (Figure 5); and distal right humerus GSP/Sangiali-1117 (Figure 5) from Sangiali 1 locality and proximal humerus with prominent head (mosaic of samples MSM-694-9 and MSM-759-9; Figure 9) were found from Pakistan. The humeri are expanded at proximal and distal ends. The ball like strongly expanded head is oriented and just attached to proximal rugosities. Proximal humerus has a V-shaped plain area just below the head while in Pakisaurus and Isisaurus the posterior convexity trending dorsoventrally is located. Proximal humerus has a plain area just below the head while the lateral and medial sides of the V-shaped plain are bended anteriorly. The deltopectoral fossa has anteroposterior thin or narrow bone. Proximal humerus has prominent head like Pakisaurus balochistani, while Isisaurus colberti have relatively less prominent head of humeri) with dominant rugosities. Saraikimasoom vitakri (like Pakisaurus balochistani and Isisaurus colberti) have less prominent medial extrusion of proximal part of medial limb than Gspsaurus pakistani which have prominent extrusion. The proximal and distal humerus has intense rugosities. The deltopectoral crest is medially inset but close to lateral profile. The deltopectoral crest is slightly deflected as oblique from dorsoventral orientation. The deltopectoral crest has a proximolateral bulge. The proximal humerus has subequal lateral and medial processes unlike Pakisaurus balochistani and Isisaurus colberti which have medial limb considerably longer. The deltopectoral fossa is closed in Saraikimasoom vitakri while open in Pakisaurus balochistani and Isisaurus colberti. The Pakisaurus humerus has expanded anteriorly exposed radial condyle which is not found in Isisaurus colberti. Saraikimasoom vitakri have anteriorly expanded radial condyle on the distal humerus while it is not expanded in Isisaurus colberti. Saraikimasoom vitakri have anteriorly expanded radial condyle have position on lateral side while the Pakisaurus balochistani have anteriorly expanded radial condyle on the approximated centre (transverse centre). Saraikimasoom vitakri have relatively transversely short proximal and distal humerus than Isisaurus colberti and Pakisaurus balochistani. Humeral midshaft cross section shape seems to be elliptical and considerably transversely small than Isisaurus colberti and Pakisaurus balochistani. The posterior side of distal humerus has a relatively deep and close groove or less broad groove (than Pakisaurus) for the adjustment of prominent olecranon process. The anterior view of the distal humerus has prominent radial condyle and posterior part is 
divided well in to two condyles like radial and ulnar condyles. This posterior central ridge or radial condyle is prominent in Pakisaurus while it is not prominent in Isisaurus. The ventral view of distal humerus is generally horizontal with rugosities. The distal humerus has relatively more thick; more expanded and exposed radial condyle anteriorly than ulnar condyle. In proximal humerus MSM-245-15 the preserved width is $25 \mathrm{~cm}$ (some portion destroyed) while distal end MSM-174-15 is $33 \mathrm{~cm}$.

Radius: The proximal radius MSM-344-4n (Figure 3) is collected from north Kinwa $4 \mathrm{n}$. The radius proximal end surface is slightly concave and oval shaped due to close articulation with fibular condyle of distal femur while proximal end surface has flat oval-shaped outline in Lusotitan atalaiensis [57]. The radius proximal end surface has a well-developed medial projection like Lusotitan atalaiensis [57]. The proximal part show slight concavity or depression on proximal view. The proximal end is expanded and has pointed projection directed medially. The proximal radius has rugosities on the dorsal view and also extending somewhat down. The rugose distal end surface is subrectangular and slightly convex. Radius shaft is nearly oval upto preserved shaft section.

Ulna: Well preserved proximal ulna MSM-78-15 (Figure 8) distal ulna? (or distal tibia?) MSM-227-15 (Figure 8) from Mari Bohri 15 locality and distal ulna MSM-252-9 (Figure 9) from Grut 9 locality were collected. The proximal ulna and distal ulna are rugose and bears a prominent olecranon process. The proximal ulna is gracile and represents triradiate structure. This triradiate limbs are relatively long but have relatively less width. The ulna is gracile. There is a marked concave depression on the proximal lateral side to cradle the head of radius. It has also depression on the medial side also. The posterior side have slight depression and almost smooth. The ulna gradually tapers toward down. Ulna has well developed olecranon process. Relative lengths of ulnar proximal condylar processes are unequal. Distal ulna is divided and broad concavity on one side and convexity on another side. Distal ulna has rugosities on the ventral view.

Metacarpals: Proximal metacarpal MSM-297-15 (Figure 8) and distal metacarpal MSM-750-15 (Figure 9) found from Mari Bohri and a metacarpal end MSM-1036-16 is found from Top Kinwa. Metacarpals are elongated and subrectangular. Distal condyle shape is undivided and has no articular rugosities, showing absence of phalanges and unguals. A proximal and distal end is expanded with subrectangle shape.

Ilium: Acetabulum MSM-166-15 (Figure 8) includes the glenoid with large pubic peduncle condyle (broken) and short and laminar ischium peduncle. Ventrally the acetabulum is long and oval and bears parallel ridges. Up of the pubis peduncle a robust subrounded broken bone is located which may join to the preacetabular process. The preacetabular process is spongy and thin (relatively less thick). The pubic peduncle is large and subovate or flat and D shape. In contrast the ischium peduncle is feeble. The acetabulum forms the embayment 
for the reception and movement of femur heads. The broken triangular part of ilia represents the parallel spongy/pneumatic texture with large open internal cells.

Pubis: The proximal pubis with glenoid surface MSM-1096-4n (Figure 3) from north Kinwa 4n, partial proximal ischium GSP/Sangiali-1116 and distal left pubis GSP/Sangiali-1117 (Figure 5) are found from mid-Sangiali 1 locality. The proximal glenoid area is quite expanded and spongy. The proximal portion is expanded on one side as the pubis of Gspsaurus pakistani while other side is platy The distal end of pubis is also expanded.

Femur: Many femora are collected from north Kinwa 4n, Mari Bohri and Sangiali 1, etc. A pair of left and right femora (left femur MSM-190-4n and partial right femur MSM-192-4n; Figure 3) were found associated with cranial and postcranial fossils the north Kinwa $4 \mathrm{n}$, left femur (proximal left femur MSN-168-15; left distal femur MSM-173-15 Figure 8) associated with some postcranial fossils from Mari Bohri 15, proximal left femur GSP/Sangiali-1118 (Figure 5) associated with postcranial skeleton, and referred proximal right femora MSM-749-15 and MSM-167-15 from Mari Bohri (Figure 5). Almost complete left femur (proximal femur MSM-178-2 and distal femur MSM-182-2 was associated vertebral, appendicular and limb materials found with from mid-Bor 2 locality. The left femur (MSM-190-4n) is complete. This femur is relatively small associated with skull and other postcranial elements showing smallest Poripuch titanosaur. An unusual and prominent feature of femur is the rectangular or subrectangular shaped cross section of femur shaft just below the femoral head. This feature can be clearly observed on section (Figure 8). This feature is feebly also found in Gspsaurus while this feature is not found in Pakisaurus and Isisaurus.

The gently with straight lateral profile of upper one third deflection of Sangiali femur is found well. The proximal end of the femur extends dorsomedially as extended and expanded subrounded head. The femoral head is significantly elevated relative to the greater trochanter. The greater trochanter forms the proximolateral corner of the proximal femur. A prominent dorsoventrally longitudinal ridge started from the posterolateral corner of greater trochanter and extends down upto mid femur and may be further downward. This ridge is sub parallel ridge to medial and lateral sides. The fourth trochanter is relatively situated upward or proximally becomes close to bend of head. The shaft of the femur is straight in anterior and lateral views. At midshaft, the femur has oval or suboval cross-section whose transversely oriented long axis is nearly 2 times (Figure 8) the length of its anteroposteriorly oriented short axis while it is 3 times in Pakisaurus balochistani femur. The distal end is bifurcated in two condyles as tibial and fibular condyles both have rugosities on ventral view. The ventral view of distal condyle has concavity or rounded groove between the two condyles while humerus has no concavity or rounded groove between the two condyles. The tibial condyle is relatively deeper and narrower than fibular con- 
dyle (including epicondyle). While the fibular condyle (including epicondyle) is relatively more wider than tibial condyle. The tibial condyle is wheel like. The fibular condyle is posteriorly divided in two sub condyles (one more expanded and one less expanded). Femoral distal condyles, articular surface shape expanded onto anterior portion as well as lateral and medial portion of femoral shaft close to distal ends. It has rugosities on the proximal and also distal ends. The constricted part of femur seems to be close to distal condyles than the proximal head portion. The preserved sector of the diaphysis is anteroposteriorly compressed, resulting in a oval or elliptical outline. In distal view, the tibial and fibular condyles are beveled anterolaterally like Gspsaurus pakistani and unlike Oceanotitan [58] which show medially-posterolaterally probably due to deformation. The tibial condyle is bigger and transversely longer than the fibular one. The tibial and fibular condyles are slightly extended to the anterior face of the femur. The epicondyle is well developed and separated from the fibular condyle by a well-defined proximodistal groove. There is no notch in between the head and greater trochanter. The length of femur (MSM-190-4n) of north kinwa exemplar is about $85-90 \mathrm{~cm}$ and width at distal condyles is $25 \mathrm{~cm}$ and proximal width of head along with greater trochanter is about $22 \mathrm{~cm}$. The distal ends of femur have rugosities which extended on shaft. The prominent feature observed here is the rectangle shaped cross section of uppermost part of shaft just below the greater tochanter. This feature is clearly observed in a proximal left femur MSN-168-15 and proximal right femur MSM-749-15 from Mari Bohri. The distal end (cumulative of tibial, fibular and epicondylar transverse width) is transversely wider than the proximal end (head and greater trochanter). The distal condyles appear to have been sheared slightly anterolaterally relative to the shaft of the femur. This is natural and not an artefact of preservation. The tibial or medial condyle is larger but narrower than the lateral condyle (fibular condyle and epicondyle). All these femora have same characters as north Kinwa femur, only difference is the size which may belong to different ontogenetic stages. The femora of Saraikimasoom and Gspsaurus of gspsaurids have same characters only size is a matter, the Saraikimasoom is small sized and Gspsaurus is medium sized, both with relatively stocky thick bones (than Isisaurus and Pakisaurus of Pakisaurids). The Saraikimasoom vitakri show straight lateral profile of medial deflection while the Pakisaurus balochistani show wavy style lateral profile of medial deflection. Further Jainosaurus (=Antarctosaurus) septentrionalis was attributed braincase, vertebrae, humeri, scapulae, fibula and femur which show dual affinity like braincase and vertebrae referable to Pakisaurus balochistani, one scapula to Isisaurus colberti, humeri have no distinct information. Only distal humeri have distinct information like expanded radial condyle or not expanded. The distal humerus with not expanded radial condyle is attributed to Isisaurus colberti while the distal humerus with expanded radial condyle is attributed to Pakisaurus balochistani, Saraikimasoom vitakri and possibly to Gspsaurus pakistani. Conclusively the referral of cranial and postcranial mate- 
rials is problem for Jainosaurus (=Antarctosaurus) septentrionalis while for other Indo-Pak titanosaurs is relatively easy because Isisaurus and Pakisaurus pakisaurids slender titanosaurs and Gspsaurus and Saraikimasoom gspsaurids stocky titanosaurs have associated materials which provides facility to assign cranial and postcranial materials.

Tibia: Fortunately four different type of key tibiae were discovered from Pakistan belonged to distinguished and distinct four titanosaur taxa from Indo-Pakistan like Isisaurus (slender tibia; transversely compressed proximal flattened tibia and transversely broad triangular shaped distal view of distal tibia) and Pakisaurus (quite slender tibia; transversely compressed proximal flattened tibia and transversely quite broad/more broader distal tibia) of pakisaurids (slender tibiae), and Gspsaurus (anteroposteriorly and transversely expanded proximal tibia; slightly elongated transversely, asymmetric biconvex lense shaped proximal tibia, and transversely expanded and anteroposteriorly compressed, subrectangle/suboval shaped distal tibia) and Saraikimasoom (quite robust, subsquare shaped with about equal anteroposterior and transverse widths of stocky proximal tibia, and transversely expanded and anteroposteriorly compressed, suboval shaped distal view of distal tibia) of gspsaurids (robust tibiae). These four diversities of key tibiae have discarded the hypothesis of only two titanosaurs taxa from Indo-Pakistan [59] and solved the longstanding controversy about the number of taxa from South Asia. Distinct and distinguished stockiest proximal left tibia MSM-246-15 from Mari Bohri 15 (Figure 8) and left tibia GSP/Sangiali-1120 (Figure 5) from Sangiali 1 were found with some associated postcranial bones. A pair of small transversely broad oval/suboval shaped distal tibia (MSM-345-4n, MSM-346-4n; Figure 3)) found from north Kinwa 4n associated with the north possesses a well-developed fibular condyle (or lateral bulge) that projects laterally. The anterior part of the condylar ridge is used for the attachement of fibula, where the posterior part of fibula articulated. This type of tibia show closely approximated mutual articulation with fibula. The upper part of the shaft of tibia is generally subcircular and slightly broader anteroposteriorly than transversely but it twists 90 degrees towards its distal end, where it is much broader transversely than anteroposteriorly (Figure 3) (Figure 9). Tibia and fibula with closely ap Kinwa skeleton of Saraikimasoom. An oval/suboval shaped distal tibia (MSM-75-9: Figure 9) was also found with some associated bones from Grut 9 locality of Dhaola Gambrak Range. Both proximal typical tibiae are well preserved, well exposed and well diagnosed however cnemial crest is destroyed. The proximal end is subrectangular/subsquare shaped and strongly robust, while oval/suboval shaped distal end is transversely broad/long. The proximal end of right tibia from Mari Bohri has the same anteroposterior width about $26 \mathrm{~cm}$ and transverse width about $26 \mathrm{~cm}$. Its preserved shaft cross section is at about $30 \mathrm{~cm}$ downward from proximal end measured anteroposterior breadth $16-17 \mathrm{~cm}$ and transverse width is $13 \mathrm{~cm}$, also revealing subcircular cross section. Its shape, proximal measurement and cross sectional measurement allowed 
its distinctions from others. The proximal tibia of Saraikimasoom vitakri matches with Lusotitan atalaiensis [57] and Lohuecotitan pandafilandi [60]. The dorsal view of proximal end has rugose surface with subrounded concavity or slight depression for the attachment of distal tibial condyle of femur. A depression is present on the anterolateral margin of the proximal end, posterior to the base of the cnemial crest. Posterior to this, the lateral bulge (fibular articular surface or condylar ridge) of the proximal end forms an additional projection. This proximolateral projection (Figure 5) (Figure 8) is also present in some sauropods, e.g. Giraffatitan [61], Diplodocus [62], Janenschia (the "second cnemial crest" of [63]: 37; SMNS 12144: P. D. Mannion personal observation in 2011), and Phuwiangosaurus [64]. The proximolateral bulge extends distally as a vertical ridge but disappears close to the level where the cnemial crest fades into the anterior surface of the shaft. The distal end of tibia forms transversely long oval shape. The distal end is strongly expanded transversely, a morphology typical of many titanosauriforms [33] [65] [66] [67] although differing from the almost equidimensional of the tibia of the somphospondylans Antarctosaurus [68] and Paluxysaurus [69] and transversely broad distal end of tibia of Pakisaurus and Isisaurus pakisaurids.

There are a sign of a second cnemial crest sensu [57] [64]. This type of second cnemial crest is observed on the anterior side of fibular articular condylar ridge like Lusotitan atalaiensis [57] and unlike Pakisaurus balochistani and Isisaurus colberti. The posterolateral surface of the cnemial crest bears a well-demarcated fibular articular facet. Bounded between $1^{\text {st }}$ cnemial crest and $2^{\text {nd }}$ cnemial crest there is low, concave, triangular surface bears pockmarked bone [59] indicative of a ligamentous connection to the anterior crest of the fibula. The proximal head of the tibia is roughly subcircular and expanded transversely and proximated mutual articulation (shared with other titanosauriforms, including Euhelopus, Erketu and Epachthosaurus). Further during cradling and articulation, the fibular anteroposterior surface rotated upto mediolateral position when approached to tibia. This is due to strong lateral expansion of tibia.

Fibula: A partial fibula (proximal left fibula GSP/Sangiali-1121; mid left fibula GSP/Sangiali-1122; Figure 5)) found from mid Sangiali 1 locality. This Fibula mostly has same features as the Gspsaurus pakistani Chota Simla fibula. The shaft cross section just below the scar is oval. The major difference of this fibula of Saraikimasoom vitakri from the Chota Simla left fibula (NHMUK R5903) of Gspsaurus pakistani is the position and location of lateral trochanter. The lateral trochanter of fibula of Saraikimasoom vitakri is positioned at the centre of shaft while the lateral trochanter of fibula of Gspsaurus pakistani is positioned close to the anterior profile of shaft.

Astragalus: An astragalus MSM-752-9 (Figure 9) associated with distal transversely broad stocky tibia, distal ulna, proximal humerus with prominent head oriented proximal extremity and caudal vertebrae were found from Grut 9 locality of Dhaola Gambrak Range. The general shape of astragalous is transversely 
long and concave or syncline with limbs type. The medial and lateral parts are truncated. The astragalus fossa at the base of ascending process is present. Astragalous posterior fossa shape is undivided. The lateral surface of the ascending process is straight inclined downward or mildly convexing profile generally inclining downward (Figure 9). This astragalous body is long and concave transversely. It forms the transversely oriented axis syncline with anterior and posterior limbs. These limbs are named as anterior limb and posterior limb due to their occurrences. The anterior limb convex maximum form ridge in the lateral one third distance from lateral corner. From maximum peak or ridge of ascending process, on both sides laterally and also medially the inclination started toward medial and lateral base. The posterior limb behavior is same as anterior limb but difference is that the posterior limb peak is lower than anterior limb. Both these limbs trend transversely separated by a elongated depression or groove which is also oriented transversely. Between the anterior and posterior ridges is a deep astragalous fossa (Figure 9).

Osteoderm: The mosaic type small oval armour bones (mosaic type oval/suboval osteoderms MSM-1095-17 (Figure 9) from Dada Pahi 17 locality of Vitakri Dome may belong to Saraikimasoom vitakri. This mosaic type armour bone $10 \times 7 \mathrm{~cm}$ in dimension made up of irregularly shaped nodule/polygon ossicles, separated by internal ducts. This plate is relatively more thick and coarse than the mosaic type armor of Gspsaurus pakistani. This plate has a large concave cut on one side may belong to prefrontal/postfrontal or any cranial element. A large oval and ellipsoidal shaped osteoderms MSM-84-7 (Figure 9) was collected from South Zubra (Basti Nala) 7 and possibly associated with the typical caudal vertebrae and mid-scapular bones of Saraikimasoom vitakri. This oval plate is among the largest known osteodermal plates of titanosaurs. This large oval plate has slight concavity and rugosities on smooth ventral surface, and rugosities on lateral and dorsal surfaces. The dorsal surface has an asymmetrical low ridge directed posterodorsally. The ossicles on the ridge area are tightly packed and directing posterodorsally. The length and width of ventral oval surface are 19 and $16 \mathrm{~cm}$ respectively, and dorsoventral depth of dorsal ridge from ventral surface to preserved apex is $12 \mathrm{~cm}$ [13] [14]. Like these large oval and rugose osteoderms were also reported from Malawi [70], Argentina [71] and India [4] [72]. Further the large ellipsoidal osteodermal plate (AMNH 1959) from India is more similar to osteoderms MSM-84-7 of Saraikimasoom vitakri from Pakistan, so osteodermal plate (AMNH 1959) from India is being referred to Saraikimasoom vitakri a small sized stocky titanosaur from Indo-Pakistan subcontinent. The reference [73] proposed that these both oval plates being assigned to pes toes of titanosaurian because its shape, length, width, rugosities, robustness and general outlines closely matches with the ungual found in pes footprints found from Pakistan [31].

Coprolites: From India diverse coprolites of dinosaurs [74] are found but from Pakistan many subcircular wheel type rounded and spongy/vesicular pieces 
with $5-7 \mathrm{~cm}$ in diameter are collected from the terrestrial Latest Cretaceous Vitakri Formation of Vitakri dome area, eastern Sulaiman foldbelt, Barkhan District, Balochistan. These five coprolite pieces (Figure 9) may belong to titanosaurian sauropods and/or probably abelisaurian theropod dinosaurs or both.

\section{Conclusion}

Due to lack of snout from Indo-Pakistan (South Asia), this finding of snout with complete teeth row from south Kinwa, Balochistan, Pakistan is providing significant features of Saraikimasoom vitakri titanosaur from Indo-Pakistan subcontinent. There is also lack of cranial and associated postcranial remains of titanosaurs in Indo-Pakistan but this finding of cranial and associated postcranial skeleton of Saraikimasoom vitakri titanosaur from north Kinwa and also many other associated skeletons from Mari Bohri, mid Sangiali, south Zubra Basti Nala and Grut localities of Pakistan provide again significant features for the comparison, evolutionary and phylogenetic studies of titanosaurs in the globe. These fossils are significant remains from Pakistan which have no parallel from India [75], so these paleobioheritage, geoheritage and their sites need preservation [76]-[80].

\section{Conflicts of Interest}

The author declares no conflicts of interest regarding the publication of this paper.

\section{References}

[1] Falconer, H. (1868) Memorandum of Two Remarkable Vertebrae. Sent by Dr. Oldham from Jubbalpur-Spilsbury's Bed Paleontological Memoirs and Notes of the Late Hugh Falconer, Volume 1, 418-419.

[2] Lydekker, R. (1877) Notes of New and Other Vertebrata from Indian Tertiary and Secondary Rocks. Geological Survey of India, 10, 30-43.

[3] Lydekker, R. (1879) Indian Pre-Tertiary Vertebrata. Part 3. Fossil Reptilia and Batrachia. Paleontologia Indica, 4, 325-326.

[4] Huene, F.V. and Matley, C.A. (1933) Cretaceous Saurischia and Ornithischia of the central provinces of India. Paleontologia Indica, 21, 1-74.

[5] Swinton, W.E. (1947) New Discoveries of Titanosaurus indicus Lyd. Annals and Magazine of Natural History, 14, 112-123. https://doi.org/10.1080/00222934708654616

[6] Jain, S.L. and Bandyopadhyay, S. (1997) New titanosaurid (Dinosauria: Sauropoda) from the Late Cretaceous of Central India. Journal of Vertebrate Paleontology, 17, 114-136. https://doi.org/10.1080/02724634.1997.10010958

[7] Sahni, A. (2001) Dinosaurs of India. National Book Trust, Delhi, 110 p.

[8] Malkani, M.S. and Anwar, C.M. (2000) Discovery of First Dinosaur Fossil in Pakistan, Barkhan District, Balochistan. Geological Survey of Pakistan Information Release, 732, 1-16.

[9] Malkani, M.S. (2006) Biodiversity of Saurischian Dinosaurs from the Latest Cretaceous Park of Pakistan. Journal of Applied and Emerging Sciences, 1, 108-140. 
[10] Malkani, M.S. (2008) Marisaurus (Balochisauridae, Titanosauria) remains from the latest Cretaceous of Pakistan. Sindh University Research Journal, 40, 55-78.

[11] Malkani, M.S. (2008) First Articulated Atlas-Axis Complex of Titanosauria (Sauropoda, Dinosauria) Uncovered from the Latest Cretaceous Vitakri Member (Dinosaur Beds) of Upper Pab Formation, Kinwa Locality of Sulaiman Basin, Pakistan. Sindh University Research Journal (Science Series), 40, 55-70.

[12] Malkani, M.S. (2003) Discovery of Partial Skull and Dentary of Titanosauria (Sauropod Dinosaur) from the Late Cretaceous Pab Formation of Vitakri Area, Barkhan District, Balochistan, Pakistan. Geological Bulletin, University of Peshawar, 36, 65-71.

[13] Malkani, M.S. (2003) Pakistani Titanosauria; Are Armoured Dinosaurs? Geological Bulletin University of Peshawar, 36, 85-91.

[14] Malkani, M.S. (2010) Osteoderms of Pakisauridae and Balochisauridae (Titanosauria, Sauropoda, Dinosauria) in Pakistan. Journal of Earth Science, 21, 198-203. https://doi.org/10.1007/s12583-010-0212-Z

[15] Malkani, M.S. (2009) New Balochisaurus (Balochisauridae, Titanosauria, Sauropoda) and Vitakridrinda (Theropoda) Remains from Pakistan. Sindh University Research Journal (Science Series), 41, 65-92.

[16] Malkani, M.S. (2010) New Pakisaurus (Pakisauridae, Titanosauria, Sauropoda) Remains and Cretaceous Tertiary (K-T) Boundary from Pakistan. Sindh University Research Journal (Science Series), 42, 39-64.

[17] Malkani, M.S. (2014) Titanosaurian Sauropod Dinosaurs from the Latest Cretaceous of Pakistan. Abstract Volume of 2 nd symposium of IGCP 608 "Cretaceous Ecosystem of Asia and Pacific", Tokyo, Japan, 4-6 September 2014, 108-111.

[18] Malkani, M.S. (2015) Titanosaurian Sauropod Dinosaurs from Pakistan. In: Zhang, Y., Wu, S.Z. and Sun, G., Eds., Abstract Volume, 12th Symposium on "Mesozoic Terrestrial Ecosystems (MTE 12), and 3rd Symposium of International Geoscience Program (IGCP 608) "Cretaceous Ecosystem of Asia and Pacific", Paleontological Museum of Liaoning/Shenyang Normal University, Shenyang, China, 15-20 August 2015, 93-98.

[19] Malkani, M.S. (2015) Dinosaurs, Mesoeucrocodiles, Pterosaurs, New Fauna and Flora from Pakistan. Geological Survey of Pakistan, Information Release, 823, 1-32.

[20] Malkani, M.S. (2019) Large Titanosaur from Indo-Pakistan Peninsula. Open Journal of Geology, 9, 635-638. https://doi.org/10.4236/ojg.2019.910061

[21] Malkani, M.S. (2019) Medium Sized Stocky Titanosaur from South Asia. Open Journal of Geology, 9, 631-634. https://doi.org/10.4236/ojg.2019.910060

[22] Malkani, M.S. (2019) Smallest Titanosaur from Indo-Pakistan Landmass. Open Journal of Geology, 9, 627-630. https://doi.org/10.4236/ojg.2019.910059

[23] Malkani, M.S. (2020) First Skull of Medium Sized Titanosaur from Indo-Pakistan Subcontinent Found from the Latest Maastrichtian Vitakri Formation of Pakistan; Associated Cranial and Postcranial Skeletons of Gspsaurus pakistani (Poripuchia, Stocky Titanosauria, Sauropoda) from Pakistan and India. Open Journal of Geology, 10. (In Press) https://doi.org/10.4236/ojg.2019.910059

[24] Malkani, M.S. (2020) Pakisaurus balochistani (Poripuchia, Slender Titanosauria, Sauropoda) Associated Skeletons from the Latest Maastrichtian Vitakri Formation of Pakistan and Referred Fossils from India; Filling of Significant Missing Links of Isisaurus colberti (Poripuchia, Slender Titanosauria, Sauropoda) Found from Pakistan. Open Journal of Geology, 10. (In Press) 
[25] Malkani, M.S. (2020) Exploration of Latest Theropods, Mesoeucrocodiles and Pterosaurs from Pakistan. In Process.

[26] Malkani, M.S. (2010) Updated Stratigraphy and Mineral Potential of Sulaiman (Mid. Indus) Basin, Pakistan. Sindh University Research Journal (Science Series), 42, 39-66.

[27] Malkani, M.S. (2019) Vitakrisaurus saraiki Theropod from South Asia. Open Journal of Geology, 9, 643-645. https://doi.org/10.4236/ojg.2019.910063

[28] Malkani, M.S. (2014) Theropod Dinosaurs and Mesoeucrocodiles from the Terminal Cretaceous of Pakistan. Abstract Volume of 2 nd Symposiums on International Geoscience Program (IGCP 608) "Cretaceous Ecosystem of Asia and Pacific", Tokyo, Japan, 4-6 September 2014, 169-172.

[29] Malkani, M.S. (2019) Induszalim bala Mesoeucrocodile from Pakistan. Open Journal of Geology, 9, 623-626. https://doi.org/10.4236/ojg.2019.910058

[30] Wilson, J.A. Malkani, M.S. and Gingerich, P.D. (2001) New Crocodyliform (Reptilia, Mesoeucrocodylia) form the Upper Cretaceous Pab Formation of Vitakri, Balochistan (Pakistan). Contributions from Museum of Paleontology, University of Michigan, 30, 321-336.

[31] Malkani, M.S. (2019) Recently Discovered Basilosaurid, Baluchithere Rhinoceros, Horses, Sea Cow, Proboscidean, Eucrocodile, Pterosaurs, Plesiosaur, Fishes, Invertebrates and Wood Fossils, Tracks and Trackways of Dinosaurs from Pakistan; Comparison of Recognized four Titanosaur Taxa of Indo-Pakistan with Madagascar. Open Journal of Geology, 9, 919-955. https://doi.org/10.4236/ojg.2019.912098

[32] Malkani, M.S. and Sun, G. (2016) Fossil Biotas from Pakistan with Focus on Dinosaur Distributions and Discussion on Paleobiogeographic Evolution of Indo-Pak Peninsula. Global Geology, 19, 230-240.

[33] Salgado, L., Coria, R.A. and Calvo, J.O. (1997) Evolution of Titanosaurids Sauropods. I: Phylogenetic Analysis Based on the Postcranial Evidence. Ameghiniana, 34, 3-32.

[34] Curry Rogers, K.A. and Forster, C.A. (2004) The Skull of Rapetosaurus krausei (Sauropoda: Titanosauria) from the Late Cretaceous of Madagascar. Journal of Vertebrate Paleontology, 24, 121-144. https://doi.org/10.1671/A1109-10

[35] Upchurch, P. (1998) The Phylogenetic Relationships of Sauropod Dinosaurs. Zoological Journal of the Linnean Society, 124, 43-103. https://doi.org/10.1111/j.1096-3642.1998.tb00569.x

[36] Wilson, J.A. and Sereno, P.C. (1998) Early Evolution and Higher Level Phylogeny of Sauropod Dinosaurs. Society of Vertebrate Paleontology Memoir, 5, 1-68. https://doi.org/10.2307/3889325

[37] Curry Rogers, K.A. and Forster, C.A. (1999) The Skull of Rapetosaurus krausei (Sauropoda: Titanosauria) from the Late Cretaceous of Madagascar. Journal of Vertebrate Paleontology, 24, 121-144. https://doi.org/10.1671/A1109-10

[38] Owen, R. (1842) Report on British Fossil Reptiles, Pt. II. Reptiles. Report of the British Association for the Advancement of Science, No. 1841, 60-204.

[39] Seeley, H.G. (1888) The Classification of the Dinosauria. British Association for the Advancement of Science, Report 1887, 698-699.

https://doi.org/10.1017/S0016756800156006

[40] Marsh, O.C. (1878) Principal Characters of American Jurassic Dinosaurs. Part I. American Journal of Science (Series 3), 16, 411-416.

https://doi.org/10.2475/ajs.s3-16.95.411 
[41] Bonaparte, J.F. and Coria, R.A. (1993) A New and Huge Titanosaur Sauropod from the Rio Limay Formation (Albian-Cenomanian) of Neuquen Province, Argentina. Ameghiniana, 30, 271-282.

[42] Wilson, J.A. and Upchurch, P. (2003) A Revision of Titanosaurus Lydekker (Dinosauria-Sauropoda), the First Dinosaur Genus with a 'Gondwanan' Distribution. Journal of Systematic Paleontology, 1, 125-160. https://doi.org/10.1017/S1477201903001044

[43] Deperet, C. (1896) Note sur les dinosauriens sauropodes et theropodes du Cretace superieur de Madagascar. Bulletin de la Societe Geologique de France, 24, 176-194.

[44] Malkani, M.S. (2017) Balochisaurus malkani and Marisaurus jeffi balochisaurid titanosaurs of Pakistan: A Review. In: Cheong, D., Lee, Y. and Kim, D., Eds., Commemoration of the 70 th Anniversary of the Geological Society of Korea, Proceedings and Field Guide Book for the Fifth International Symposium of International Geoscience Programme IGCP Project 608 "Cretaceous Ecosystems and Their Responses to Paleoenvironmental Changes in Asia and the Western Pacific", Jeju Island, Korea, 22-28 October 2017, 40-43.

[45] Malkani, M.S., Wilson, J.A. and Gingerich, P.D. (In Process) New Fossil Assemblages of Titanosaurian Sauropod from the Upper Cretaceous Mid-Sangiali 1 Locality of Vitakri Dome, Barkhan District, Balochistan (Pakistan).

[46] Malkani, M.S. (2006) Lithofacies and Lateral Extension of Latest Cretaceous Dinosaur Beds from Sulaiman Foldbelt, Pakistan. Sindh University Research Journal (Science Series), 38, 1-32.

[47] Malkani, M.S. (2019) Cretaceous Stratigraphy of Pakistan. Open Journal of Geology, 9, 671-673. https://doi.org/10.4236/ojg.2019.910071

[48] Nowinski A. (1971) Nemegtosaurus mongoliensis n. gen. n. sp. (Sauropoda) from the Uppermost Cretaceous of Mongolia. Palaeontologica Polonica, 25, 57-81.

[49] Kurzanov, S.M. and Bannikov, A.F. (1983) A New Sauropod from the Upper Cretaceous of Mongolia. Paleontological Journal, 2, 90-96.

[50] Jacobs, L.L., Winkler, D.A., Downs, W.R. and Gomani, E.M. (1993) New Material of an Early Cretaceous Titanosaurid Sauropod Dinosaur from Malawi. Palaeontology, 36, 523-534.

[51] Le Loueff, J. (1995) Ampelosaurus atacis (nov. gen., nov. sp.), un Nouveau Titanosauridae (Dinosauria, Sauropoda) du Cretace superieur de la Haute Vallee de L'Aude (France). Comptes Rendus de L'Academie des Sciences de Paris (ser. IIa), 321, 693-699.

[52] Mathur, U.B. and Srivastava, S. (1987) Dinosaur Teeth from Lameta Group (Upper Cretaceous) of Kheda District, Gujurat. Journal of the Geological Society of India, 29, 554-566.

[53] Wilson, J.A., Malkani, M.S. and Gingerich, P.D. (2005) A Sauropod Braincase from the Pab Formation (Upper Cretaceous, Maastrichtian) of Balochistan, Pakistan. Gondwana Geological Magazine, 8, 101-109.

[54] Wilson, J.A. (2002) Sauropod Dinosaur Phylogeny: Critique and Cladistic Analysis. Zoological Journal of the Linnean Society, 136, 217-276. https://doi.org/10.1046/j.1096-3642.2002.00029.x

[55] Curry Rogers, K.A. (2005) Titanosauria: A Phylogenetic Overview. In: Curry Rogers, K. and Wilson, J.A., Eds., The Sauropods. Evolution and Paleobiology, University of California Press, Berkeley, CA, 50-103. https://doi.org/10.1525/california/9780520246232.003.0003 
[56] Smith, J.B., Vann, D.R. and Dodson, P. (2005) Dental Morphology and Variation in Theropod Dinosaurs: Implications for the Taxonomic Identification of Isolated Teeth. The Anatomical Record, Part A, 285, 699-736. https://doi.org/10.1002/ar.a.20206

[57] Mannion, P.D., Upchurch, P., Barnes, R.N. and Mateus, O. (2013) Osteology of the Late Jurassic Portuguese Sauropod Dinosaur Lusotitan Atalaiensis (Macronaria) and the Evolutionary History of Basal Titanosauriformes. Zoological Journal of the Linnean Society, 168, 98-206. https://doi.org/10.1111/zoj.12029

[58] Mocho, P., Royo-Torres, R. and Ortega, F. (2019) A New Macronarian Sauropod from the Upper Jurassic of Portugal. Journal of Vertebrate Paleontology, 2019, e1578782. https://www.tandfonline.com/loi/ujvp20 https://doi.org/10.1080/02724634.2019.1578782

[59] Wilson, J.A., Barrett, P.M. and Carrano, M.T. (2011) An Associated Partial Skeleton of Jainosaurus cf. septentrionalis (Dinosauria: Sauropoda) from the Late Cretaceous of Chhota Simla, Central India. Palaeontology, 54, 981-998. https://doi.org/10.1111/j.1475-4983.2011.01087.x

[60] Díez Díaz, V., Mocho, P., Paramo, A., Escaso, F., Marcos-Fernandez, F. and Sanz, J.L. (2016) A New Titanosaur (Dinosauria, Sauropoda) from the Upper Cretaceous of Lo Hueco (Cuenca, Spain). Cretaceous Research, 68, 49-60. https://doi.org/10.1016/j.cretres.2016.08.001

[61] Janensch, W. (1961) Die Gliedmaszen und Gliedmaszengürtel der Sauropoden der Tendaguru-Schichten. Palaeontographica, 3, 177-235.

[62] Hatcher, J.B. (1901) Diplodocus (Marsh): Its Osteology, Taxonomy, and Probable Habits, with a Restoration of the Skeleton. Memoirs of the Carnegie Museum, 1, 1-63. https://doi.org/10.5962/bhl.title.46734

[63] Bonaparte, J.F., Heinrich, W.-D. and Wild, R. (2000) Review of Janenschia Wild, with the Description of a New Sauropod from the Tendaguru Beds of Tanzania and a Discussion on the Systematic Value of Procoelous Caudal Vertebrae in the Sauropoda. Palaeontographica, Abteilung A, 256, 25-76.

[64] Martin, V., Suteethorn, V. and Buffetaut, E. (1999) Description of the Type and Referred Material of Phuwiangosaurus sirindhornae Martin, Buffetaut and Suteethorn, 1994, a Sauropod from the Lower Cretaceous of Thailand. Oryctos, 2, 39-91.

[65] Upchurch, P. (1999) The Phylogenetic Relationships of the Nemegtosauridae (Saurischia, Sauropoda). Journal of Vertebrate Paleontology, 19, 106-125. https://doi.org/10.1080/02724634.1999.10011127

[66] Upchurch, P., Barrett, P.M. and Dodson, P. (2004) Sauropoda. In: Weishampel, D.B., Dodson, P. and Osmólska, H., Eds., The Dinosauria, 2nd Edition, University of California Press, Berkeley, CA, 259-324. https://doi.org/10.1525/california/9780520242098.003.0015

[67] Mannion, P.D. and Calvo, J.O. (2011) Anatomy of the Basal Titanosaur (Dinosauria, Sauropoda) Andesaurus delgadoi from the Mid-Cretaceous (Albian-Early Cenomanian) Río Limay Formation, Neuquén Province, Argentina: Implications for Titanosaur Systematics. Zoological Journal of the Linnean Society, 163, 155-181. https://doi.org/10.1111/j.1096-3642.2011.00699.x

[68] Mannion, P.D. and Otero, A. (2012) A Reappraisal of the Late Cretaceous Argentinean Sauropod Dinosaur Argyrosaurus superbus, with a Description of a New Titanosaur Genus. Journal of Vertebrate Paleontology, 32, 614-638. https://doi.org/10.1080/02724634.2012.660898

[69] Rose, P.J. (2007) A New Titanosauriform Sauropod (Dinosauria: Saurischia) from 
the Early Cretaceous of Central Texas and Its Phylogenetic Relationships. Palaeontologica Electronica, 10, 1-65.

[70] Gomani, E.M. (2005) Sauropod Dinosaurs from the Early Cretaceous of Malawi, Africa. Palaeontologia Electronica, 1-37. http://palaeo-electronica.org

[71] Powell, J.E. (2003) Revision of South American Titanosaurids Dinosaurs: Palaeobiological, Palaeobiogeographical and Phylogenitic Aspects. Records of the Queen Victoria Museum, 111, 1-173.

[72] Demic, M.D. and Wilson, J.A. (2009) The Titanosaur (Dinosauria, Sauropoda) Osteoderm Record: Review and First Definitive Specimen from India. Journal of Vertebrate Paleontology, 29, 165-177. https://doi.org/10.1671/039.029.0131

[73] Malkani, M.S. (2018) Mesozoic Vertebrates from Pakistan and Their Paleobiogeographic Affinities. In: Martin, T., Schellhorn, R. and Schultz, J.A., Eds., Proceedings of 13 th symposium on Mesozoic Terrestrial Ecosystems and Biota (MTE13), University of Bonn, Germany, 77-79.

[74] Ghosh, P., Bhattacharya, S.K., Sahni, A., Kar, R.K., Mohabey, D.M. and Ambwani, K. (2003) Dinosaur Coprolites from the Late Cretaceous Maastrichtian) Lameta Formation of India: Isotopic and Other Markers Suggesting a $\mathrm{C}_{3}$ Plant Diet. Cretaceous Research, 24, 743-750. https://doi.org/10.1016/j.cretres.2003.08.002

[75] Wilson, J.A., Mohabey, D.M., Lakra, P. and Bhadran, A. (2019) Titanosaur (Dinosauria, Sauropoda) Vertebrae from the Upper Cretaceous Lameta Formation of Western and Central India. Contributions from the Museum of Paleontology, University of Michigan, 33, 1-27.

[76] Malkani, M.S. and Mahmood, Z. (2017) Stratigraphy of Pakistan. Geological Survey of Pakistan, Memoir Volume, 24, 1-134.

[77] Malkani, M.S. and Mahmood, Z. (2017) Mineral Resources of Pakistan: Provinces and Basins Wise. Geological Survey of Pakistan, Memoir Volume, 25, 1-179.

[78] Malkani, M.S. and Mahmood, Z. (2016) Revised Stratigraphy of Pakistan. Geological Survey of Pakistan, Record Volume, 127, 1-87.

[79] Malkani, M.S. and Mahmood, Z. (2016) Mineral Resources of Pakistan: A Review. Geological Survey of Pakistan, Record Volume, 128, 1-90.

[80] Malkani, M.S. (2011) Stratigraphy, Mineral Potential, Geological History and Paleobiogeography of Balochistan Province, Pakistan. Sindh University Research Journal (Science Series), 43, 269-290. 